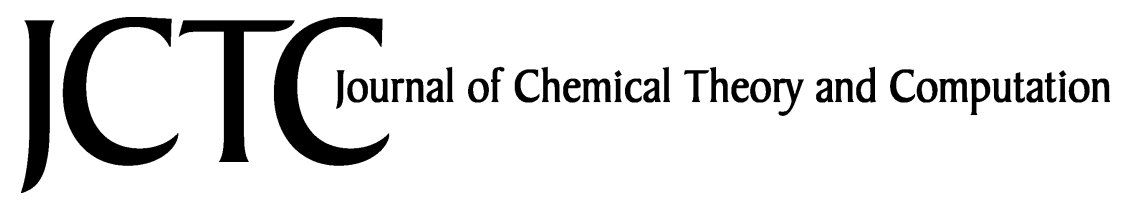

\title{
Radical Addition to Thioketones: Computer-Aided Design of Spin Traps for Controlling Free-Radical Polymerization
}

\author{
Hugh Chaffey-Millar, ${ }^{\dagger}$ Ekaterina I. Izgorodina, ${ }^{\ddagger}$ Christopher Barner-Kowollik, ${ }^{*}, \dagger$ and \\ Michelle L. Coote*, \\ Centre for Advanced Macromolecular Design, School of Chemical Sciences and \\ Engineering, The University of New South Wales, Sydney, New South Wales 2052, \\ Australia, and ARC Centre of Excellence in Free-Radical Chemistry and \\ Biotechnology, Research School of Chemistry, Australian National University, \\ Canberra, Australian Capital Territory 0200, Australia
}

Received April 6, 2006

\begin{abstract}
An extensive study has been undertaken of the radical affinity of a number of thioketones $(S=C(X)(Y))$ with the aim of selecting combinations of $X$ and $Y$ that render the substrate suitable for the mediation of free radical polymerizations. Using high level ab initio molecular orbital calculations, enthalpies at $0 \mathrm{~K}$ were determined for the reactions $\mathrm{R}^{\bullet}+\mathrm{S}=$ $\mathrm{C}(\mathrm{X})(\mathrm{Y}) \rightarrow \mathrm{R}-\mathrm{S}-\mathrm{C} \cdot(\mathrm{X})(\mathrm{Y})$ for $\mathrm{R}^{\bullet}=\mathrm{CH}_{3}, \mathrm{CH}_{2} \mathrm{OH}, \mathrm{CH}_{2} \mathrm{CN}$, and benzyl, in reactions with a variety of thioketones, including various combinations of $X$ and $Y$ taken from $\mathrm{H}, \mathrm{CH}_{3}, \mathrm{Ph}, \mathrm{CN}, \mathrm{OCH}_{3}$, $\mathrm{C}\left(\mathrm{CH}_{3}\right)_{3}$ and para-CN-Ph as well as several compounds in which the $\mathrm{X}$ and $\mathrm{Y}$ are bonded, namely xanthene-9-thione, fluorine-9-thione, and cyclopenta[def]phenanthrene-4-thione. The radical affinities of the various thioketones has been discussed in terms of the radical stabilization energies (RSEs) of the adduct radicals and stabilities of the $S=C$ bonds. From these studies, the two thioketones $S=C(C N)(P h)$ and fluorene-9-thione were selected as being potentially suitable candidates for use in controlling free radical polymerizations due to their high radical affinities. However, based on transition state theory calculations of the rate coefficients for homo/ copolymerization of $\mathrm{S}=\mathrm{C}(\mathrm{CN})(\mathrm{Ph})$ with itself and styrene at $333.15 \mathrm{~K}$, this substrate was deemed to be unsuitable, as it was likely to undergo side reactions. Instead, the more-hindered fluorine9-thione was identified as the ideal thioketone, and the equilibrium constants at $333.15 \mathrm{~K}$ for the reactions of the styryl and vinyl acetate dimer radicals with fluorine-9-thione were made. These two reactions, at $333.15 \mathrm{~K}$, displayed equilibrium constants in the vicinity of $10^{14} \mathrm{~L} \mathrm{~mol}^{-1}$ and $10^{16} \mathrm{~L} \mathrm{~mol}^{-1}$, respectively, indicating that there is significant scope within the thioketone class of compounds to mediate free radical polymerizations via radical stability alone.
\end{abstract}

\section{Introduction}

During the past two decades there has been much interest in the use of free radicals as a reactive center for the polymerization of a variety of monomers. Conventionally, this

* Corresponding author e-mail: c.barner-kowollik@unsw.edu.au (C.B.K.) and mcoote@rsc.anu.edu.au (M.L.C.).

The University of New South Wales.

$\doteqdot$ Australian National University. process has resulted in average molecular weights that are approximately constant with conversion. More recently, a number of methods have been devised to control free-radical polymerization processes such that (in the ideal case) the average molecular weight grows linearly with conversion. An additional benefit of these controlled radical polymerizations (CRP) is the ability to tailor the chemical structure of chain ends and to reduce the polydispersity index (PDI) from 
Scheme 1. Reactions of a Generic Radical Polymerization as Well as Those of the RAFT and Thioketone Addition Processes
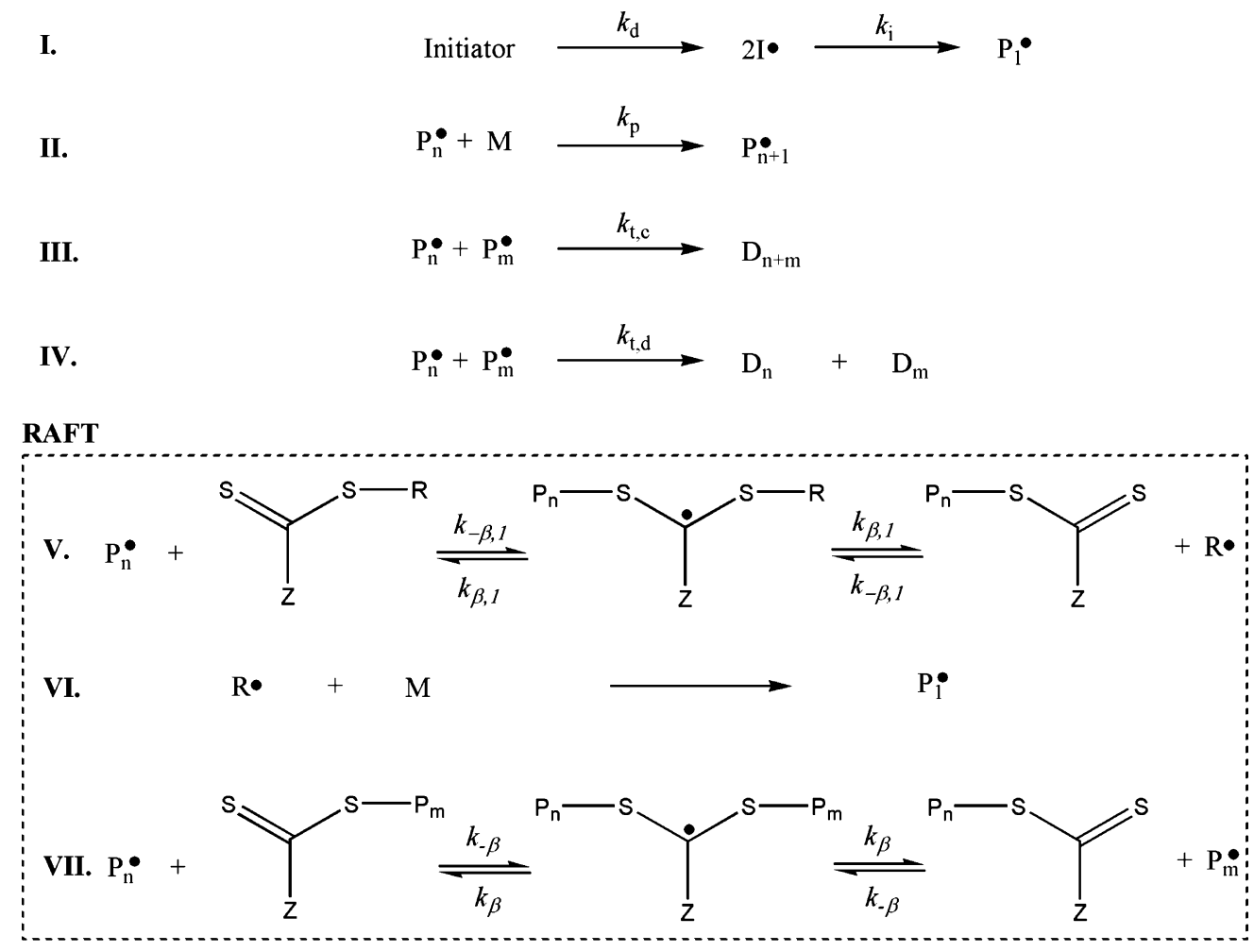

Thioketone Addition

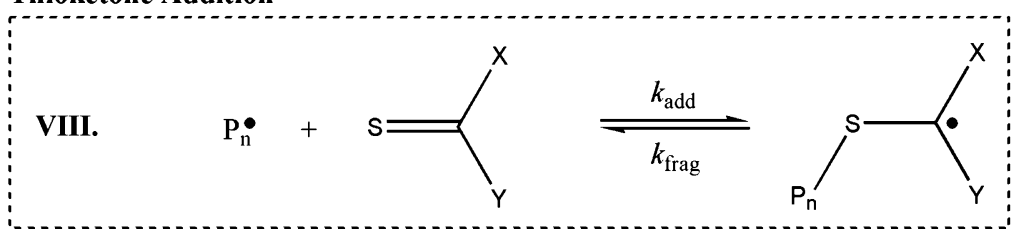

values of 1.5-2.0 (for conventional radical polymerization) down to values approaching 1.05 (for CRP).

Three of the most successful techniques which have emerged are nitroxide mediated polymerization (NMP), ${ }^{1}$ atom transfer radical polymerization (ATRP), ${ }^{2,3}$ and reversible addition-fragmentation chain-transfer polymerization (RAFT). ${ }^{4,5}$ All of these techniques afford living behavior by maintaining a population of dormant chains that is high in concentration relative to the number of radicals and hence the number of terminated chains that accumulate. The first two methods, NMP and ATRP, achieve this by reduction of the radical concentration. RAFT, however, can operate successfully with a radical concentration that is the same as a conventional radical polymerization-control is instead achieved through the creation of a population of dormant chains that is superimposed on that of its radical counterparts. The technique can, however, benefit from a reduction in radical concentration, and this is brought about with the use of RAFT agents that form an intermediate that is relatively stable toward fragmentation. More specifically, and with reference to Scheme 1, this stability is reflected by a high equilibrium constant $K=k_{-\beta} / k_{\beta}$ in reaction VII. It should be pointed out that this stability has been the subject of considerable scientific debate; ${ }^{6,7,10}$ however, there is a body of consistent experimental and theoretical evidence that suggests that high radical stability is a physical reality when the RAFT agent is substituted with radical-stabilizing Zgroups, such as phenyl. ${ }^{8-11}$

In a recent communication, ${ }^{12}$ it was shown that molecules with radical stabilizing (but not chain transfer) features in their substrate can lead to controlled behavior in the polymerization of styrene and that a reversible radical trapping process is a possible mechanism for the origin of the characteristic increase of average molecular weight with conversion. The experiments featured a large initial increase in molecular weight followed by a highly linear subsequent increase in molecular weight with conversion. This was akin to what is termed hybrid behavior in the RAFT process and, in the reversible trapping mechanism, would be expected to occur if the equilibrium constant $\left(K=k_{\text {add }} / k_{\text {frag }}\right)$ for the reversible trapping reaction (Scheme 1.VIII) fell into the approximate range of $10^{5}-10^{6} \mathrm{~L} \mathrm{~mol}^{-1}$. High level ab initio calculations for the addition of model polystyryl radicals to the di-tert-butyl thioketone agent (Scheme 1.VIII) indicated that the equilibrium constant $\left(7.0 \cdot 10^{4} \mathrm{~L} \mathrm{~mol}^{-1}\right)$ did indeed fall into this approximate range, providing some support for the proposed mechanism. ${ }^{12}$

Although controlled radical polymerization has been achieved using thioketone spin traps, for a practical polymerization process it would be desirable to eliminate the hybrid 
behavior and in this way improve the molecular weight control. To this end, it is necessary to identify thioketone spin traps for which the equilibrium constants are significantly higher. However, the equilibrium constant should not be too large, since this can lead to severe retardation/ inhibition phenomena. Kinetic studies of the related nitroxide mediated free-radical polymerizations (NMP, which is based on the same key idea as the present process but uses a radical spin trap) indicate that $K$ should be around $10^{9} \mathrm{~L} \mathrm{~mol}^{-1}$ in order to effect an efficient living process. ${ }^{6}$ There are various other characteristics that are desirable if thioketones are to be used in controlling polymerizations. As well as a high equilibrium constant for the reversible radical trapping process, chain transfer to and copolymerization of the thioketone compounds must be absent. For this reason it is likely that substrates with bulky substituents (such as phenyl or tert-butyl) might be practically suitable. Additionally, since the dormant species bears a radical, it is essential that termination of two dormant species does not occur to a significant extent. This is another reason bulky substituents are likely to be advantageous. Finally, we note that it is important that the rate coefficient for addition of the propagating radical to the thioketone is substantially higher than that of the monomer. As in the case of RAFT polymerization, thioketones are suitable control agents in this respect because $\mathrm{C}=\mathrm{S} \pi$ bonds are considerably weaker than $\mathrm{C}=\mathrm{C}$ bonds, due to the poorer overlap between the $\mathrm{p}$-orbitals on first row carbon and second row sulfur atoms, and consequently their singlet-triplet excitation energies are considerably smaller. ${ }^{13,14}$

The fact that the dormant species in thioketone-mediated polymerizations bear radicals also brings about the complication that at the conclusion of the polymerization, these species may still be "active". It might be possible in the future to devise some chemical means to terminate these active species, analogous to the quenching of anionic polymerization mediums with a carboxylic acid to give all chains a hydrogen end group. In this regard there is a greater degree of complication as compared to RAFT. Another complicating factor in the radical spin trapping process is that all polymerizing chains originate from initiator fragments. This is in contrast to the RAFT process, one of whose crucial features is the fragmenting and reinitiating R-group. As a result, rather than most chains having nearly the same length, molecular weights will be more evenly distributed between the maximum and minimum values present in the system, meaning that with a slowly decomposing initiator, very low polydispersities $(<1.3)$ cannot be achieved.

Despite these challenges, there are several reasons for interest in this polymerization system. First it may in the future be possible to provide some degree of control over previously difficult to control monomers since the presence of only a single thiyl group provides greater flexibility for fine-tuning the reactivity of the molecular substrate. Second, there is academic interest in that it offers an experimental scenario in which it should be possible to elucidate relative radical stabilities of propagating and trapped radicals. Third, with a greater understanding of the effect of the above two variables, it might be possible to adjust the RAFT process, extending its control to a wider variety of systems, such as those involving monomers with very high or very low reactivities.

To facilitate the further experimental study of this new process, the purpose of the current paper is to use high-level ab initio molecular orbital calculations to design improved thioketone spin traps for controlling free-radical polymerization. We initially survey the effects of substituents on the enthalpies for the trapping of various radicals by a range of thioketone molecules, so as to identify combinations of substituents that are likely to maximize the equilibrium constant of the trapping reaction. This complements and extends our earlier studies of substituent effects in the RAFT process, for which the presence of the additional thiyl substituent was found to dominate the structure-reactivity trends. ${ }^{11-17}$ In the present work it is possible to vary both thiocarbonyl substituents and in this way target a wider range of stabilities and reactivities. Having identified potential combinations of substituents, we then select the thioketone spin traps most likely to resist copolymerization and radicalradical termination on the basis of steric factors. We then evaluate their likely performance in a polymerizing system through direct calculation of their equilibrium constants for trapping of model propagating radicals and also their copolymerization propagation rate coefficients.

\section{Theoretical Procedures}

Definitions. In the present work we study the effects of substituents on the stabilities of the adduct-radicals using the standard radical stabilization energies (RSEs) ${ }^{18,19}$ For a radical $R^{\cdot}$, it is defined as the enthalpy of the hydrogen abstraction reaction

$$
\mathrm{R}^{\bullet}+\mathrm{CH}_{3}-\mathrm{H} \rightarrow \mathrm{R}-\mathrm{H}+\mathrm{CH}_{3} \cdot
$$

As discussed previously, ${ }^{15,20,21}$ in using the RSE to measure the stability of the radical we make the implicit assumption that the effect of the substituent on the stability of the closed shell compound is negligible and therefore cancels. While this assumption can be invalid in some situations (such as the study of phosphoranyl radicals ${ }^{20}$ ), it has been found to provide a reasonable qualitative guide to the stability of carbon-centered radicals. ${ }^{15,21}$ Within this framework, a positive value indicates that $\mathrm{R}^{\bullet}$ is more stable than $\mathrm{CH}_{3}{ }^{\circ}$ and vice versa.

The thiocarbonyl bond stability in a compound $\mathrm{S}=\mathrm{CXY}$ can be estimated relative to that of thioformaldehyde ( $\mathrm{S}=$ $\mathrm{CH}_{2}$ ) as the enthalpy of the following isodesmic reaction, analogous to that defined previously for RAFT agents. ${ }^{15}$

$$
\mathrm{S}=\mathrm{CXY}+\mathrm{CH}_{4} \rightarrow \mathrm{S}=\mathrm{CH}_{2}+\mathrm{CH}_{2} \mathrm{XY}
$$

Once again, a positive value of the enthalpy for the isodesmic reaction indicates that the $\mathrm{X} / \mathrm{Y}$ substituents stabilize the thiocarbonyl bond relative to that in thioformaldehyde. As in the case of the RSEs, in using the enthalpy to study the stability of the thiocarbonyl compound it is assumed that the $\mathrm{X}, \mathrm{Y}$ substituents do not destabilize the reference compound $\mathrm{CH}_{2} \mathrm{XY}$. As a result, this measure will at best offer only a qualitative guide to relative stabilities but has 


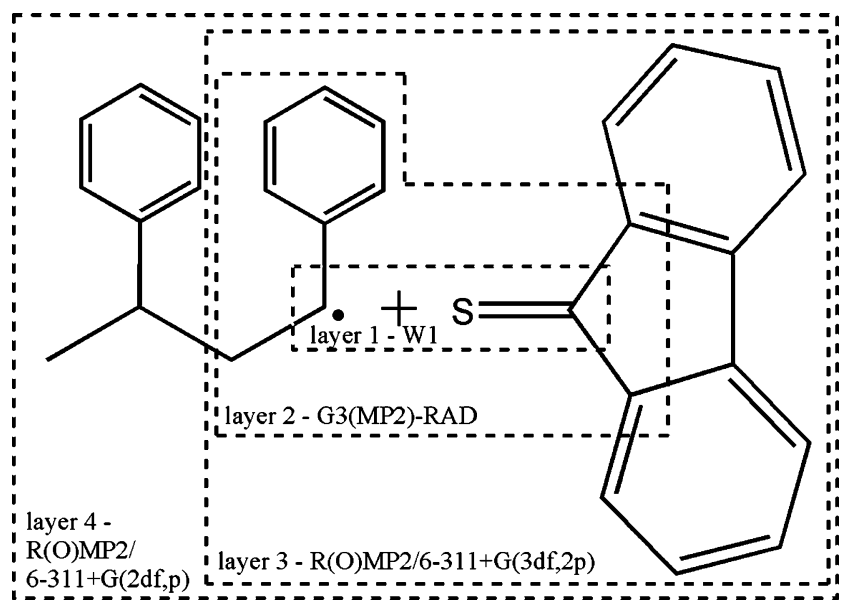

Figure 1. Example of the use of the ONIOM method to approximate a high level of theory energy calculations. In this method, only the core is calculated at the highest level of theory, which the effect of the substituents being accounted for at lower levels of theory. This allows approximations of higher levels of theory for which computations of the full system would render the problems intractable.

nonetheless proven useful in predicting the behavior of RAFT agents toward radical addition. ${ }^{15}$

Computational Methods. Ab initio molecular orbital theory and DFT calculations were carried out using GAUSSIAN 98, ${ }^{22}$ GAUSSIAN 03, ${ }^{23}$ GAMESS-US, ${ }^{24}$ and MOLPRO $2000.6 .^{25}$ Unless noted otherwise, calculations on radicals were performed with an unrestricted wave function. In cases where a restricted-open-shell wave function was used, it is designated with an R prefix. All enthalpies, RSEs, and agent stabilities were calculated at $0 \mathrm{~K}$; all equilibrium constants and kinetic parameters were evaluated at $333.15 \mathrm{~K}$.

Calculations were performed at a high level of theory, selected on the basis of previous assessment studies for radical addition to $\mathrm{C}=\mathrm{S}$ double bonds. ${ }^{26,27}$ Geometries and vibrational frequencies were obtained at the B3-LYP/6-31G(d) level of theory, and conformational searches for the global minimum energy structure were also performed at this level of theory. Improved energies were then calculated, using an ONIOM method ${ }^{27}$ to approximate the $\mathrm{W} 1^{28,29}$ level of theory. This operated by calculating only the core reaction $\mathrm{CH}_{3}{ }^{\bullet}+$ $\mathrm{S}=\mathrm{CH}_{2} \rightarrow \mathrm{CH}_{3}-\mathrm{S}-\mathrm{CH}_{2}{ }^{\bullet}$ at the $\mathrm{W} 1$ level of theory and then correcting the effect of the substituents using a less computationally intensive procedure, G3(MP2)-RAD. ${ }^{30}$ When even this method proved too computationally expensive, a threelayer ONIOM method was used in which the energies of the final layer of substituents were calculated at the RMP2/ $6-311+\mathrm{G}(3 \mathrm{df}, 2 \mathrm{p})$ level of theory. We have previously shown that, provided all forming and breaking bonds and all $\alpha$-substituents on the attacking radical are included in the core (as in Figure 1), this approach provides excellent approximations to high-level calculations on the full system. ${ }^{27}$ To assist in the qualitative rationalization of the results, charge and (where relevant) spin density distributions within selected thioketones and their adduct radicals were calculated on the basis of a natural bond orbital (NBO) population analysis, carried out in GAUSSIAN at the B3-LYP/6$311+\mathrm{G}(3 \mathrm{df}, 2 \mathrm{p})$ level of theory using the density $=$ current keyword.

For the agents selected as being potentially good radical trapping agents in an experimental scenario, the equilibrium constants were calculated for their reaction with model propagating species at the experimentally realistic temperature of $333 \mathrm{~K}$. Rate coefficients for propagation of the thioketone adduct radicals (via addition to monomer and addition to thioketone agents) were also calculated to assess whether such side reactions were likely to be operative. Equilibrium constants $(K)$ and rate coefficients $(k)$ were calculated using the optimized geometries, frequencies, and $\mathrm{W} 1$-corrected energies in conjunction with the following standard textbook formulas. ${ }^{31}$

$$
K(T)=\left(c^{\circ}\right)^{\Delta n} e^{(-\Delta G / R T)}=\left(c^{\circ}\right)^{\Delta n}\left(\frac{\prod_{\text {products }} Q_{j}}{\prod_{\text {reactants }} Q_{i}} e^{(-\Delta E / R T)}\right.
$$

$$
\begin{gathered}
k(T)=\kappa(T) \frac{k_{\mathrm{B}} T}{h}\left(c^{\circ}\right)^{1-m} e^{(-\Delta G \ddagger / R T)}= \\
\kappa(T) \frac{k_{\mathrm{B}} T}{h}\left(c^{\circ}\right)^{1-m} \frac{Q_{\ddagger}}{\prod_{\text {reactions }} Q_{i}} \mathrm{e}^{(-\Delta E \ddagger / R T)}
\end{gathered}
$$

In these formulas, $\kappa(T)$ is the tunneling correction factor, $T$ is the absolute temperature, $k_{\mathrm{B}}$ is Boltzmann's constant, $h$ is Planck's, $c^{\circ}$ is the standard unit of concentration $\left(\mathrm{mol} \mathrm{L}{ }^{-1}\right)$, $R$ is the universal gas constant, $m$ is the molecularity of the reaction, and $\Delta n$ the change in moles upon reaction, $Q^{\ddagger}, Q_{i}$, and $Q_{j}$ are the molecular partition functions of the transition structure, reactant $i$ and product $j$, respectively, $\Delta G^{\ddagger}$ is the Gibb's free energy of activation, $\Delta G$ is the Gibb's free energy of reaction, $\Delta E^{\ddagger}$ is the $0 \mathrm{~K}$, zero-point energy corrected energy barrier for the reaction, and $\Delta E$ is the $0 \mathrm{~K}$, zeropoint energy corrected energy change for the reaction. The value of $c^{\circ}$ depends on the standard-state concentration assumed in calculating the thermodynamic quantities (and translational partition function). The tunneling coefficient $\kappa(T)$ corrects for quantum effects in motion along the reaction path and is close to unity in the systems of interest. ${ }^{14}$ Molecular partition functions $\left(Q_{i}\right)$ were calculated using the B3-LYP/6-31G(d) geometries and frequencies in conjunction with the standard textbook formulas, based on the statistical thermodynamics of an ideal gas. ${ }^{31}$

As outlined previously, ${ }^{11,14}$ for these types of reactions (and indeed other radical addition reactions ${ }^{32}$ ), the harmonic oscillator model is not an adequate approximation for many modes of vibration that correspond to rotations (typically those less than $300 \mathrm{~cm}^{-1}$ ). Therefore, for the calculations of the equilibrium constants, all low frequency torsional modes were treated separately as hindered internal rotations, using the standard procedure described elsewhere. ${ }^{11,14}$ In the case of the propagation rate calculations, the errors in the harmonic oscillator approximation would be expected to 
Table 1. Radical Stabilization Energies (RSEs) for Thioketone Adduct Radicals, Enthalpies for the Methyl Trapping Reaction $\left(\mathrm{CH}_{3} \cdot+\mathrm{S}=\mathrm{CXY} \rightarrow \mathrm{CH}_{3} \mathrm{~S}^{\cdot} \mathrm{CXY}\right),{ }^{a}$ and Thioketone Bond Stability

\begin{tabular}{|c|c|c|c|c|c|}
\hline \multicolumn{3}{|c|}{$\mathrm{S}=\mathrm{CXY} \mathrm{Y}^{b}$} & \multirow[b]{2}{*}{$\begin{array}{c}\mathrm{RSE}^{c} \\
\left(\mathrm{~kJ} \mathrm{~mol}^{-1}\right)\end{array}$} & \multirow[b]{2}{*}{$\begin{array}{c}\Delta H \\
\left(\mathrm{~kJ} \mathrm{~mol}^{-1}\right)\end{array}$} & \multirow[b]{2}{*}{ 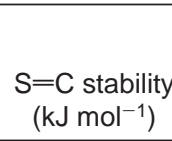 } \\
\hline no. & $x$ & $\mathrm{Y}$ & & & \\
\hline 1 & $\mathrm{H}$ & $\mathrm{H}$ & 40.8 & -123.7 & 0.0 \\
\hline 2 & $\mathrm{Me}$ & $\mathrm{Me}$ & 10.1 & -94.7 & 60.3 \\
\hline 3 & tert-butyl & $\mathrm{H}$ & 44.2 & -106.7 & 38.1 \\
\hline 4 & $\mathrm{CN}$ & $\mathrm{H}$ & 88.1 & -168.1 & -1.7 \\
\hline 5 & $\mathrm{OMe}$ & $\mathrm{H}$ & 56.6 & -53.4 & 103.3 \\
\hline 6 & $\mathrm{OMe}$ & $\mathrm{OMe}$ & 42.3 & -12.1 & 140.4 \\
\hline 7 & phenyl & $\mathrm{H}$ & 82.7 & -137.0 & 49.9 \\
\hline 8 & tert-butyl & tert-butyl & 39.9 & -91.3 & 37.3 \\
\hline 9 & $\mathrm{CN}$ & $\mathrm{CN}$ & 107.3 & -193.3 & 7.7 \\
\hline 10 & $\mathrm{CN}$ & phenyl & 115.0 & -169.7 & 47.8 \\
\hline 11 & $\mathrm{OMe}$ & phenyl & 82.3 & -75.9 & 127.4 \\
\hline 12 & phenyl & phenyl & $102.7^{e}$ & $-139.8^{e}$ & 71.7 \\
\hline 13 & (xanthene-9-thione) & & $125.2^{e}$ & $-138.3^{e}$ & $101.7^{f}$ \\
\hline 14 & phenyl & $\mathrm{Me}$ & 81.3 & -124.5 & 64.5 \\
\hline 15 & (fluorene-9-thione) & & $108.5^{e}$ & $-151.3^{e}$ & 76.0 \\
\hline 16 & p-CN-phenyl & p-CN-phenyl & $112.0^{e}$ & $-149.0^{e}$ & $65.9^{f}$ \\
\hline 17 & (phenanthrene-4-thione) & & $110.0^{e}$ & $-156.0^{e}$ & $69.0^{f}$ \\
\hline
\end{tabular}

${ }^{a}$ Enthalpies were calculated at an approximate W1 level obtained using an ONIOM approach in conjunction with the G3(MP2)-RAD level of theory and (where necessary) RMP2/6-311+G(3df,2p). The W1 core used for all structures was $\mathrm{CH}_{3}{ }^{\circ}+\mathrm{S}=\mathrm{CH}_{2}$, and unless noted otherwise G3(MP2)-RAD was used for the full system. ${ }^{b}$ Optimized geometries were obtained using B3-LYP/6-31G(d), and energies include scaled B3$\mathrm{LYP} / 6-31 \mathrm{G}(\mathrm{d})$ zero-point energy corrections. See Figures 2 and 3 for structures. ${ }^{c}$ Defined as the enthalpy change of the reaction given in eq 1. ${ }^{d}$ Defined as the enthalpy change of the reaction given in eq 2. ${ }^{e}$ Substrate used as the G3(MP2)-RAD outer core when applying the ONIOM method was $\mathrm{S}=\mathrm{C}(\mathrm{Ph})\left(\mathrm{CH}_{3}\right) \cdot{ }^{f}$ Substrate used as the $\mathrm{G} 3(\mathrm{MP} 2)-\mathrm{RAD}$ outer core was $\mathrm{S}=\mathrm{C}(\mathrm{Ph})_{2}$.

cancel to some extent (due to the early transition structures). ${ }^{14}$ Moreover, for the propagation calculations we required only order-of-magnitude accuracy, to assess the likely interference of copolymerization side reactions. For these reasons, for the propagation rate calculations, we adopted the less computationally intensive harmonic oscillator model. However, the more accurate hindered rotor model was used for the calculation of the equilibrium constants.

We have recently shown that the above methodology (when using the hindered rotor model) is capable of achieving chemical accuracy for radical addition to thioketones. For example, Scaiano and Ingold have reported an experimental equilibrium constant (based on photolysis studies) of $1.2 \times$ $10^{6} \mathrm{~L} \mathrm{~mol}^{-1}$ for the addition of tert-butyl radicals to di-tertbutyl thioketone at $25^{\circ} \mathrm{C}$. The theoretical equilibrium constant of $7.9 \times 10^{5} \mathrm{~L} \mathrm{~mol}^{-1}$ obtained using the theoretical procedure outlined above is in good agreement with experiment, the theoretical number being slightly lower possibly due to the neglect of solvent effects. ${ }^{12}$

\section{Results and Discussion}

Enthalpies for ${ }^{-} \mathrm{CH}_{3}$ radical addition to a wide range of thioketones ( $\mathrm{S}=\mathrm{CXY} ; \mathrm{X}, \mathrm{Y}=\mathrm{H}, \mathrm{H} ; \mathrm{CH}_{3}, \mathrm{CH}_{3} ; \mathrm{C}\left(\mathrm{CH}_{3}\right)_{3}, \mathrm{H}$; $\mathrm{CN}, \mathrm{H} ; \mathrm{OCH}_{3}, \mathrm{H} ; \mathrm{OCH}_{3}, \mathrm{OCH}_{3} ; \mathrm{Ph}, \mathrm{H} ; \mathrm{C}\left(\mathrm{CH}_{3}\right)_{3}, \mathrm{C}\left(\mathrm{CH}_{3}\right)_{3} ; \mathrm{CN}$,$\mathrm{CN} ; \mathrm{CN}, \mathrm{Ph}, \mathrm{OCH}_{3}, \mathrm{Ph} ; \mathrm{Ph}-\mathrm{O}-\mathrm{Ph} ; \mathrm{Ph}-\mathrm{Ph}$; para-CN-Ph,para$\mathrm{CN}-\mathrm{Ph}$; phenanthrene; see also Table 1) have been calculated at $0 \mathrm{~K}$ and placed in Table 1. Corresponding enthalpies for the addition of substituted radicals $\left(\mathrm{CN}-\mathrm{CH}_{2}{ }^{\circ}, \mathrm{HO}-\mathrm{CH}_{2}{ }^{\circ}\right.$, $\left.\mathrm{Bz}^{\circ}\right)$ are shown in Table 2. To assist in the qualitative rationalization of the results, radical stabilization energies (RSEs) of the adduct radicals and $\mathrm{C}=\mathrm{S}$ bond stabilities of thioketones are also included in Table 1. Geometries of the adduct radicals for each series of reaction are shown in Figures 2 and 3, respectively; complete geometries of all species in the form of Gaussian archive entries are provided in the Supporting Information.

The exothermicities for ${ }^{\circ} \mathrm{CH}_{3}$ addition to thioketones, together with stabilities of the thioketones and their adduct radicals, are plotted in order of increasing exothermicity in Figure 4. Inspection of Figure 4 shows that the exothermicity for the methyl trapping reaction depends on the stabilities of both the adduct radical and the thioketone agent, with the most effective agents combining high adduct stabilities with low agent stabilities. In what follows we first explore how to optimize each of these properties in turn for the case of ${ }^{\circ} \mathrm{CH}_{3}$ radical addition, and we then consider the additional effect on the enthalpy when the electronic properties of the attacking radical are varied. Finally, we use the results of Tables 1 and 2 to design improved thioketone agents for controlling the polymerization and then test them computationally for the polymerization of styrene and also vinyl acetate.

Radical Stability. As expected, the radical stabilization energy of an adduct-radical is particularly sensitive to the type of substituents, with RSEs ranging from $10.1 \mathrm{~kJ} \mathrm{~mol}^{-1}$ (adduct of thioacetone) to well over $100 \mathrm{~kJ} \mathrm{~mol}^{-1}$ (in the case of many of the phenyl and/or cyano-substituted species). It can be further noted that the substrates with at least one substituent capable of delocalizing the unpaired electron all have an RSE in excess of $80 \mathrm{~kJ} \mathrm{~mol}^{-1}$, while in most cases those without such a substituent have an RSE falling below $40 \mathrm{~kJ} \mathrm{~mol}^{-1}$. In the four simplest compounds (i.e. those in which one of the substituents is a hydrogen), the largest stabilization is afforded by the cyano-substituent, and cyano- 
Table 2. Enthalpies at $0 \mathrm{~K}$ for the Methyl Trapping Reaction $(\mathrm{R} \cdot \mathrm{S}=\mathrm{CXY} \rightarrow \mathrm{RS} \cdot \mathrm{CXY})^{\mathrm{a}}$ and Radical Stabilization Energies (RSEs) for the Adduct Radicals of $\mathrm{R}^{\bullet}$ and $\mathrm{S}=\mathrm{C}(\mathrm{CN})_{2}$

\begin{tabular}{|c|c|c|c|c|c|}
\hline no. & structure $^{b}$ & $\begin{array}{c}\mathrm{Me} \\
\Delta H \\
\left(\mathrm{~kJ} \mathrm{~mol}^{-1}\right)\end{array}$ & $\begin{array}{c}\mathrm{CN}-\mathrm{CH}_{2} \\
\Delta H \\
\left(\mathrm{~kJ} \mathrm{~mol}^{-1}\right)\end{array}$ & $\begin{array}{c}\mathrm{HO}-\mathrm{CH}_{2} \\
\Delta H \\
\left(\mathrm{~kJ} \mathrm{~mol}^{-1}\right)\end{array}$ & $\begin{array}{c}\mathrm{Bz} \\
\Delta H \\
\left(\mathrm{~kJ} \mathrm{~mol}^{-1}\right)\end{array}$ \\
\hline 3 & $\mathrm{~S}=\mathrm{C}\left(\mathrm{C}\left(\mathrm{CH}_{3}\right)_{3}\right)_{2}$ & -91.3 & -65.9 & -91.0 & $-43.6^{c}$ \\
\hline 10 & $\mathrm{~S}=\mathrm{C}(\mathrm{CN})(\mathrm{Ph})$ & -169.7 & -111.5 & -166.3 & $-128.3^{c}$ \\
\hline 11 & $\mathrm{~S}=\mathrm{C}(\mathrm{OMe})(\mathrm{Ph})$ & -75.9 & -48.2 & -76.2 & $-41.8^{c}$ \\
\hline 12 & $\mathrm{~S}=\mathrm{C}(\mathrm{Ph})(\mathrm{Ph})$ & $-139.8^{e}$ & $-114.1^{d}$ & $-137.6^{d}$ & $-95.0^{c}$ \\
\hline 9 & $\mathrm{~S}=\mathrm{C}(\mathrm{CN})_{2}$ & -193.3 & -136.7 & -186.0 & -153.1 \\
\hline 9 (RSE) & $\mathrm{R}-\mathrm{SC} \cdot(\mathrm{CN})_{2}$ & 107.3 & 109.4 & 108.1 & 114.0 \\
\hline
\end{tabular}

${ }^{a}$ Enthalpies were calculated at an approximate W1 level obtained using an ONIOM approach in conjunction with the G3(MP2)-RAD level of theory and (where necessary) RMP2/6-311+G(3df,2p). The W1 core used for all structures was $\mathrm{CH}_{3}{ }^{\circ}+\mathrm{S}=\mathrm{CH}_{2}$, and unless noted otherwise G3(MP2)-RAD was used for the full system. ${ }^{b}$ Optimized geometries were obtained using B3-LYP/6-31G(d), and energies include scaled B3LYP/6-31G(d) zero-point energy corrections. See Figures 2 and 3 for structures. ${ }^{c}$ The G3(MP2)-RAD outer core used was $B z^{*}+\mathrm{S}=\mathrm{CH}_{2}$, with the effect of the outer layer of substituents calculated at RMP2/6-311+G(3df,2p). ${ }^{d}$ The G3(MP2)-RAD outer core used was $\mathrm{R}^{\bullet}+\mathrm{S}=\mathrm{C}(\mathrm{CH})_{2}$, with the effect of the outer layer of substituents calculated at RMP2/6-311+G(3df,2p). ${ }^{e}$ The G3(MP2)-RAD outer core used was $\mathrm{CH}_{3}{ }^{*}+$ $\mathrm{S}=\mathrm{C}(\mathrm{ph})\left(\mathrm{CH}_{3}\right)$, with the effect of the outer layer of substituents calculated at RMP2/6-311+G(3df,2p).

substituted substrates prove in general to have the highest stabilities. This is due to the $\pi$-accepting ability of the cyano group, which affords a captodative interaction with the lone pair donor thiyl group.

In contrast to the $\pi$-accepting groups, the lone pair donor methoxy substituents are less stabilizing, despite the fact that they show similar radical stabilizing properties in isolation. This feature was noted previously in our study of RAFTadduct radicals ${ }^{15}$ and arises because the lone pair donor thiyl group, though stabilizing, results in the unpaired electron occupying a higher energy orbital than $2 \mathrm{p}\left(\mathrm{C}^{\bullet}\right) .^{33}$ As a result, the stabilizing interaction with subsequent lone pair donor groups is progressively weakened due to the increasing the energy gap between the lone pair and the unpaired electron. In the present work, we note that the first lone pair donor group (the thiyl substituent in the adduct of $\mathrm{CH}_{3} \mathrm{SCH}_{2}{ }^{\circ}$ ) affords a stabilization of $40.8 \mathrm{~kJ} \mathrm{~mol}^{-1}$, the second (the methoxy group in $\left.\mathrm{CH}_{3} \mathrm{SCH}\left(\mathrm{OCH}_{3}\right)^{\circ}\right)$ affords an additional stabilization of only $15.8 \mathrm{~kJ} \mathrm{~mol}^{-1}$, and the third (the additional methoxy group in $\left.\mathrm{CH}_{3} \mathrm{SC}\left(\mathrm{OCH}_{3}\right)_{2}{ }^{\circ}\right)$ affords no additional stabilization and actually destabilizes the radical, relative to $\mathrm{CH}_{3} \mathrm{SCH}\left(\mathrm{OCH}_{3}\right)^{\circ}$, due to the increasing sigma withdrawal.

Comparing the ${ }^{\circ} \mathrm{CH}_{3}$ adducts of $\mathrm{S}=\mathrm{CH}(\mathrm{Ph})$ with $\mathrm{S}=$ $\mathrm{C}(\mathrm{Ph})_{2}$, a somewhat surprising effect of the second phenyl group is a reduction in the RSE. First, it might be possible that there is a reduced $\pi$-accepting stabilizing effect due to steric factors causing a reduction in the planarity of the phenyl groups at the radical center. Second, close inspection of the optimized geometry of $\mathrm{CH}_{3}-\mathrm{S}^{\bullet}(\mathrm{Ph})_{2}$ reveals that in contrast to that for $\mathrm{CH}_{3}-\mathrm{S}^{\bullet} \mathrm{H}(\mathrm{Ph})$, the methyl group, rather than adopting a well spaced trans conformation, is angled considerably out of the plane formed at the radical center. As a result, there is less efficient overlap of the p-type lone pair on the sulfur with the $2 \mathrm{p}\left(\mathrm{C}^{*}\right)$ and hence reduced stabilization from this substituent. In support of this we note that when we compare the RSE of the $\mathrm{S}=\mathrm{C}(\mathrm{CN})_{2}$ adduct with that of its monosubstituted analogue $\mathrm{S}=\mathrm{CH}(\mathrm{CN})$, it can be seen that the second substituent does now increase the stability of the adduct radical though it still does not afford the same increase in stabilization as was provided by the first. In this case the $\mathrm{CN}$ substituent is much smaller than the phenyl group and therefore much less affected by steric interactions.

We also note that this steric interaction may also help to explain why the thioacetone adduct has a lower radical stability than the thioformaldehyde adduct, despite the presence of additional radical-stabilizing methyl groups in the former case, and why the adduct of the di-tert-butyl thioketone has a lower radical stability than the corresponding monosubstituted thioketone. For example, we consider the geometries of the adduct radicals of both di-tert-butyl thione and tert-butyl thione. In the former, the newly formed $\mathrm{C}-\mathrm{S}$ bond is nearly at right angles to the plane at the radical center, whereas for the latter it is essentially planar. It can be said, therefore, that the radical on the methyl adduct of tert-butyl thione is experiencing stabilization from lone pair donation of the adjacent sulfur atom and that this is absent in the radical adduct of di-tert-butyl thione. This is clearly seen in a reduction in the spin density at sulfur, which decreases from -0.23 in the $\mathrm{CH}_{3} \mathrm{SCH}_{2}{ }^{\bullet}$ radical and -0.19 in the $\mathrm{CH}_{3}$ $\mathrm{SCH}\left(\mathrm{C}\left(\mathrm{CH}_{3}\right)_{3}\right)^{\bullet}$ radical to only -0.01 in the $\mathrm{CH}_{3} \mathrm{SC}$ $\left(\mathrm{C}\left(\mathrm{CH}_{3}\right)_{3}\right)_{2}{ }^{\bullet}$ radical. This loss of the lone pair donation effect is partially (but not wholly) compensated for by the increased hyperconjugative stabilization from the additional tert-butyl group, resulting in a small net destabilization of the adduct radical. This is evident in the fact that the spin density at the formal radical center increases only marginally from -0.79 for $\mathrm{CH}_{3} \mathrm{SCH}_{2}{ }^{\bullet}$ and -0.78 for $\mathrm{CH}_{3} \mathrm{SCH}\left(\mathrm{C}_{(}\left(\mathrm{CH}_{3}\right)_{3}\right)^{\bullet}$ to -0.87 for $\mathrm{CH}_{3} \mathrm{SC}\left(\mathrm{C}\left(\mathrm{CH}_{3}\right)_{3}\right)_{2}$.

Given these steric effects, it is interesting therefore to look at the conformation of $\mathrm{CH}_{3}-\mathrm{S}^{\bullet}(\mathrm{Ph}-\mathrm{O}-\mathrm{Ph})$. Here, the phenyl groups are held in plane by a linking oxygen atom. The attacking methyl radical is almost perpendicular to the plane of the phenyls, meaning that the p-type lone pair on the sulfur has very little overlap with and stabilization of the radical. This represents a compromise between the energetic cost of steric repulsion of the methyl by the phenyl group and that of the reduced stabilization of the radical by the p-type sulfur lone pair, it now being perpendicular to the $2 \mathrm{p}\left(\mathrm{C}^{\bullet}\right)$ orbital. In forming this linked compound, we have strengthened the electron accepting ability of the phenyls at the expense of the electron donating ability of the sulfur lone pair. Nonetheless, the former effect dominates and leads to an increase of 
1.

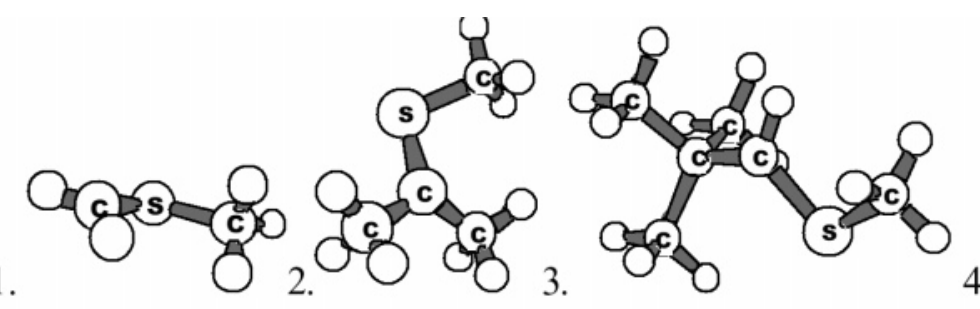

4.
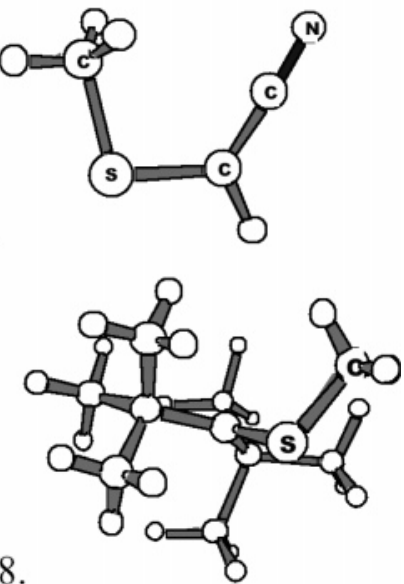

8.
5.

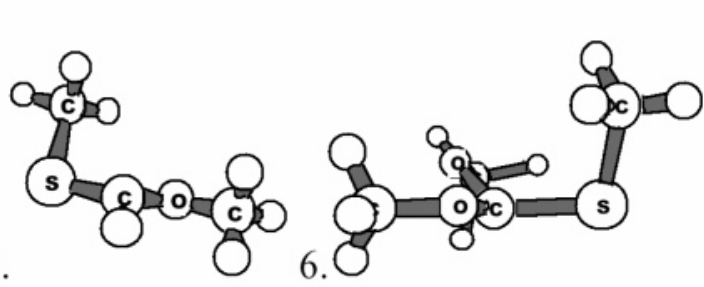

7.

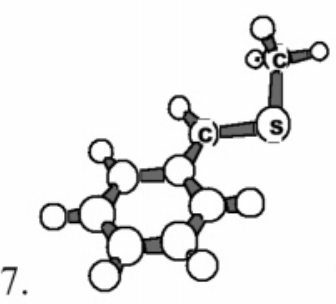

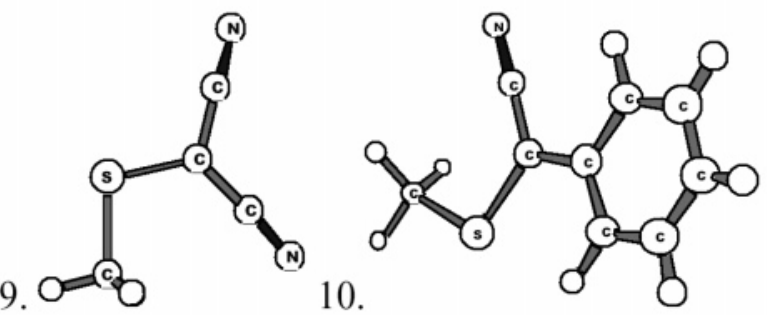

11.

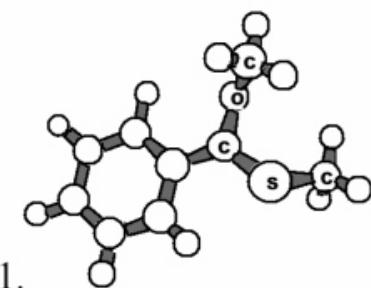

12.

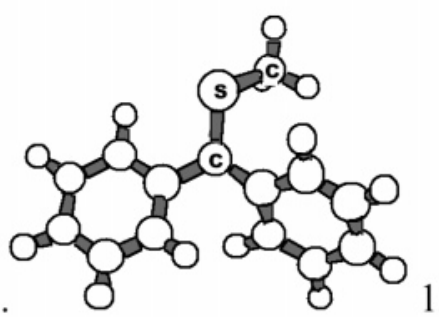

13.

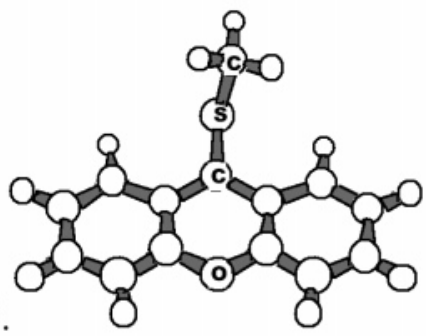

14.

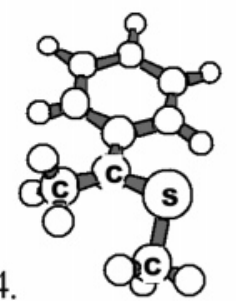

15.

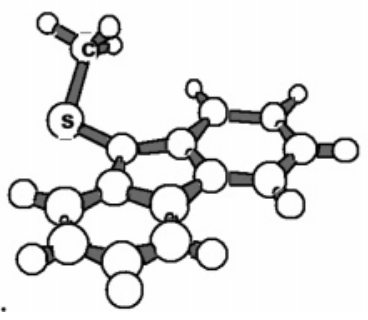

16.

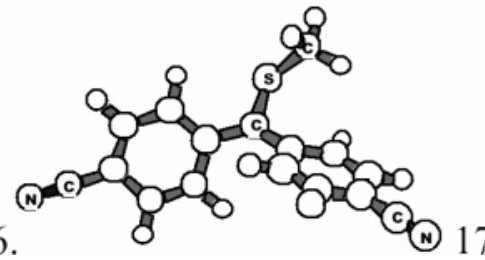

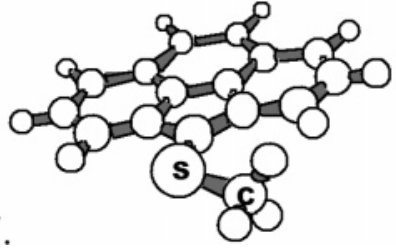

Figure 2. Optimized geometries of methyl radical adducts for each substrate. Geometry optimizations and conformation scans were carried out at the level of theory B3-LYP/6-31G(d).

approximately $22 \mathrm{~kJ} \mathrm{~mol}^{-1}$ in the RSE of the adduct radical of xanthene-9-thione, compared with the other twin-phenyl bearing compound, thiobenzophenone. However, the enthalpies for methyl trapping of these two compounds are similar in both cases because the increased stability of the adduct radical is countered by a concurrent increase in the stability of the thiocarbonyl compound due to the presence of the lone pair donor oxygen atoms (see below). To probe this further, calculations were also made for fluorene-9-thione and cyclopenta[def]phenanthrene-4-thione, for which the lone pair donor oxygen atoms were absent. These also showed an increase in the RSE of the adduct radicals (as in the case of the xanthene-9-thione) but without the significant increase in the stability of the thiocarbonyl compounds. As a result, they showed significant improvements in their methyl radical trapping capabilities, with cyclopenta[def]phenanthrene-4thione showing the greatest improvement.

In summary, all substrates with $\pi$-accepting groups (such as cyano, phenyl, and other aromatic ring systems) demonstrate radical stabilities that are high relative to compounds without $\pi$-accepting features in their substrate. Differences within this series appear to be due to the degree of delocalization and how well the sulfur lone pair can be utilized to stabilize the radical in the adduct. It seems likely that the best results are attained either when the $\pi$ accepting group is small and compact (as in the cyano substituted analogues) and/or the radical center is incorporated into an aromatic ring system that enforces planarity and thereby improves the ability of the $\pi$-system to accept the unpaired electron. 
I:
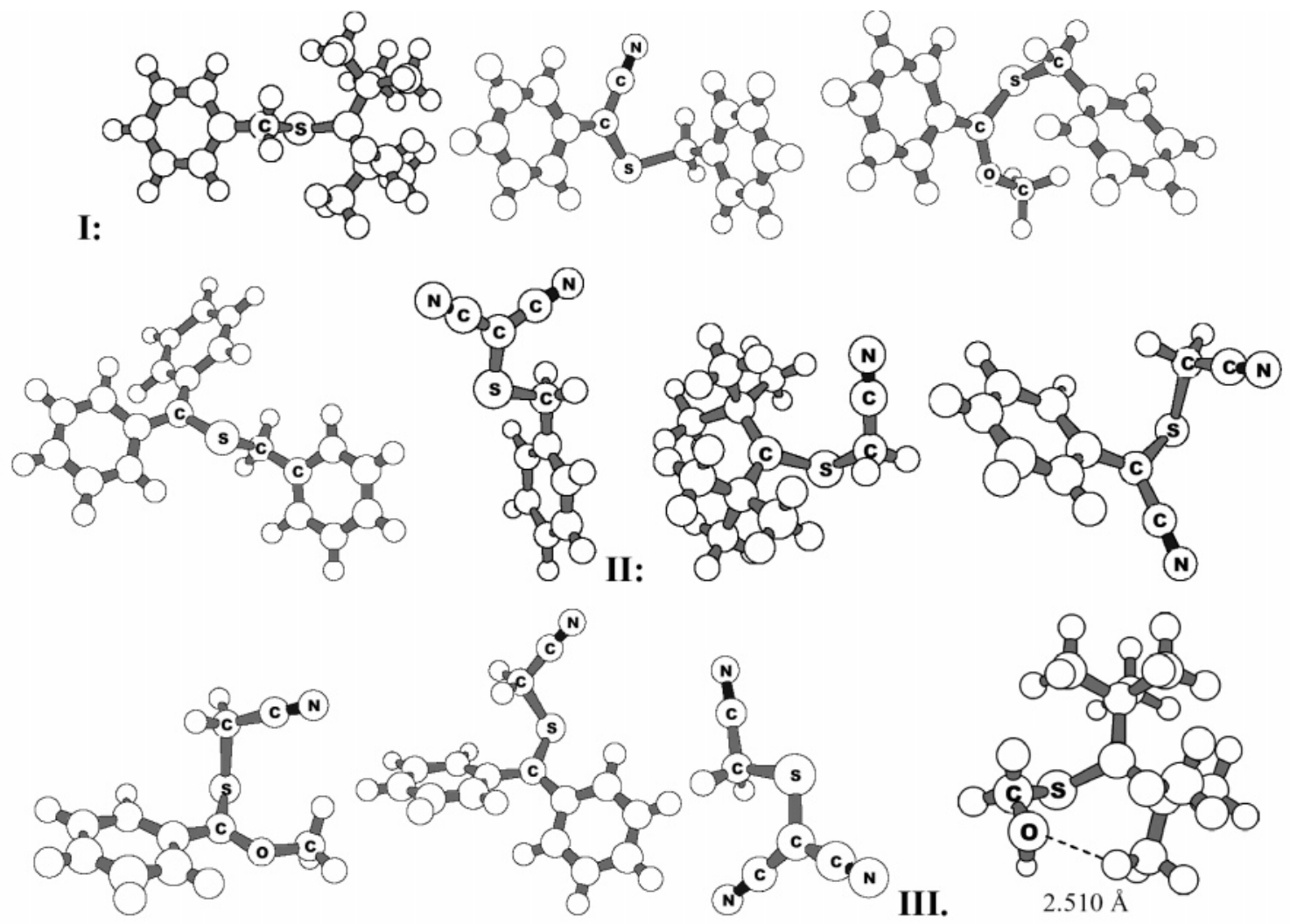

III.
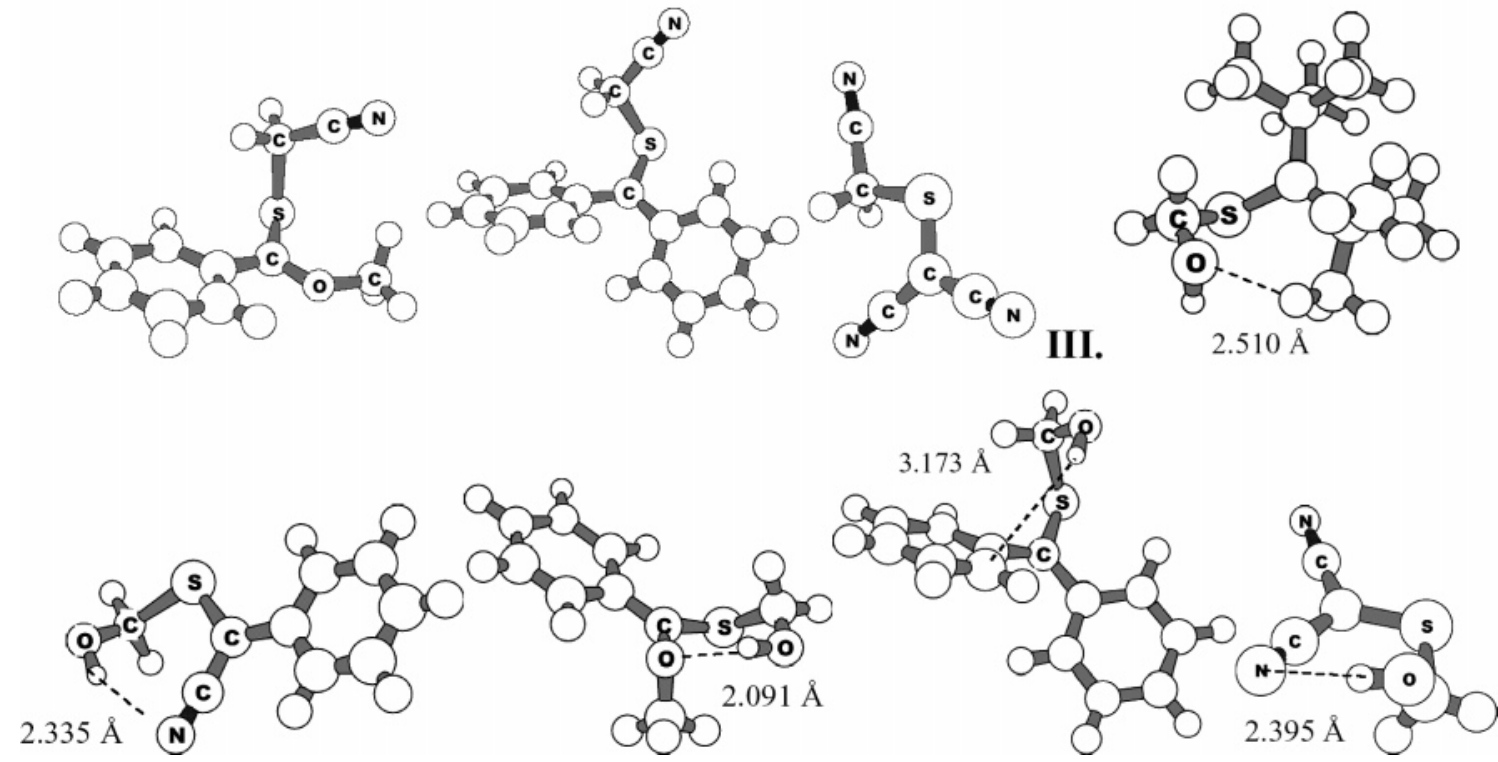

Figure 3. Optimized geometries of benzyl (I), cyanomethyl (II), and hydroxymethyl (III) radical adducts for selected substrates. Geometry optimizations and conformation scans were carried out at the level of theory B3-LYP/6-31G(d).

Thioketone Stability. As in the case of our earlier study of RAFT agents, ${ }^{15}$ we find that the $\mathrm{C}=\mathrm{S}$ bond of the thioketone agents is strongly stabilized by lone pair donating groups (such as $\mathrm{OCH}_{3}$ ) and weakly stabilized by $\pi$ or pseudo- $\pi$ donor groups (such as phenyl or alkyl groups). The stabilizing effect of lone pair donor groups is readily understood in terms of the possible resonance contributors to the thiocarbonyl compound as follows. ${ }^{5}$

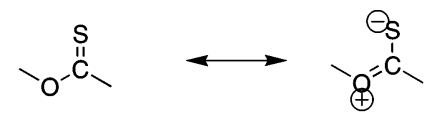

The $\pi$ or pseudo- $\pi$ donor groups are less stabilizing because they are much weaker electron donors. As in the case of RAFT agents, ${ }^{15}$ we also find that the thioketones are destabilized by steric interactions. Thus for example, the stabilizing effect of a single (electron donating) tert-butyl group is $38.1 \mathrm{~kJ} \mathrm{~mol}^{-1}$; however, the addition of the second group actually slightly destabilizes the thioketone (by approximately $1 \mathrm{~kJ} \mathrm{~mol}^{-1}$ ). In a similar manner, the stabilizing

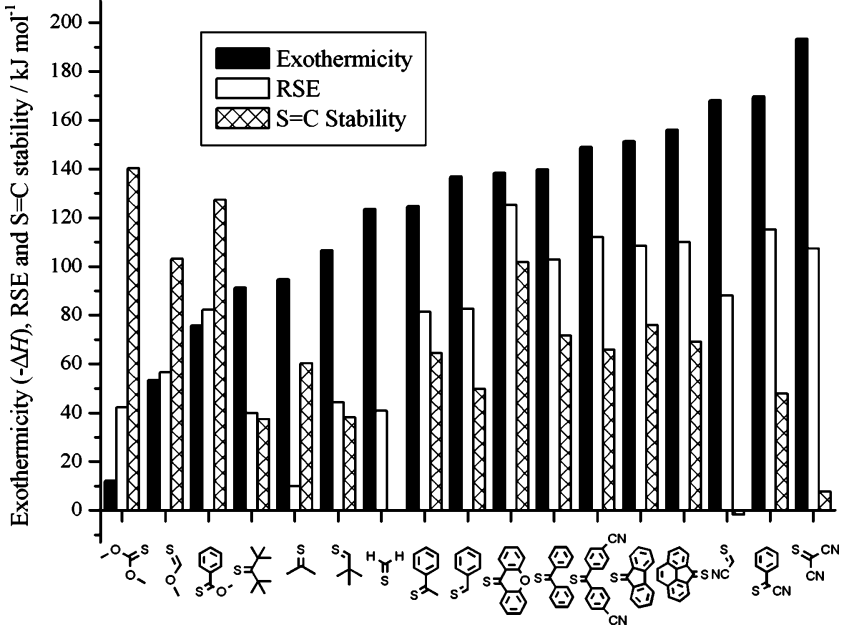

Figure 4. Exothermicities (i.e., $-\Delta H$ ) for trapping of the methyl radical at $0 \mathrm{~K}$ by all substrates studied (black bars); radical stabilization energies (RSEs) for the adduct radicals $\left(\mathrm{CH}_{3}-\mathrm{S}-\mathrm{C} \cdot(\mathrm{X})(\mathrm{Y})\right)$ (white bars); and stability of the $\mathrm{S}=\mathrm{C}$ bond (hatched bars). The values in this figure directly reflect those reported in Table 1. 
effect of two phenyl substituents $\left(71.7 \mathrm{~kJ} \mathrm{~mol}^{-1}\right)$ is much less than that sum of their isolated effects $\left(99.8 \mathrm{~kJ} \mathrm{~mol}^{-1}\right)$.

In our previous study of RAFT agents, ${ }^{15}$ we found that $\sigma$-withdrawing substituents (such as $\mathrm{CN}$ or $\mathrm{CF}_{3}$ ) destabilize the $\mathrm{C}=\mathrm{S}$ bond by inhibiting resonance with the lone pair donor thiyl group of the dithioester. In the thioketones of the present work, this resonance is already absent (as there is no thiyl substituent), and their effect is much smaller (in some cases negligible). Thus, for example, $\mathrm{S}=\mathrm{C}(\mathrm{CN}) \mathrm{H}$ is only $1.7 \mathrm{~kJ} \mathrm{~mol}^{-1}$ less stabilized than $\mathrm{S}=\mathrm{CH}_{2}, \mathrm{~S}=\mathrm{C}(\mathrm{CN}) \mathrm{Ph}$ is only $2.1 \mathrm{~kJ} \mathrm{~mol}^{-1}$ less stabilized than $\mathrm{S}=\mathrm{C}(\mathrm{H}) \mathrm{Ph}$, and the para-cyano-substituted thioketone, $\mathrm{S}=\mathrm{C}(\mathrm{p}-\mathrm{CN}-\mathrm{Ph})$, is only $5.8 \mathrm{~kJ} \mathrm{~mol}^{-1}$ less stabilized than the corresponding unsubstituted analogue, $\mathrm{S}=\mathrm{C}(\mathrm{Ph})_{2}$. However, one might expect stronger destabilizing effects (more in line with those seen in RAFT agents) if the cyano substituents were included in the presence of a second lone pair donor group, such as $\mathrm{OCH}_{3}$.

Interestingly, the di-cyano-substituted thioketone appears to be weakly stabilized (by $7.7 \mathrm{~kJ} \mathrm{~mol}^{-1}$ ) relative to $S=$ $\mathrm{CH}_{2}$, despite the fact that the monosubstituted analogue $\mathrm{S}=$ $\mathrm{CH}(\mathrm{CN})$ was not. This apparently unphysical result would seem to indicate that the isodesmic reaction used to measure stabilities of the thioketones contains an influence from the stabilities of the reference compounds (in this case $\mathrm{CH}_{4}, \mathrm{CH}_{3}-$ $\mathrm{CN}$, and $\mathrm{CH}_{2} \mathrm{CN}_{2}$ ). Indeed the reaction, $2 \mathrm{CH}_{3} \mathrm{CN} \rightarrow \mathrm{CH}_{2}-$ $\mathrm{CN}_{2}+\mathrm{CH}_{4}$, is actually endothermic by $31.1 \mathrm{~kJ} \mathrm{~mol}^{-1}$, implying that the observed increase in the stabilization energy of $\mathrm{S}=\mathrm{C}(\mathrm{CN})_{2}$ is probably due to the lower inherent stability of $\mathrm{CH}_{2} \mathrm{CN}_{2}$. This serves to illustrate the cautionary remarks made in the Theoretical Procedures section concerning the use of isodesmic reactions to measure stabilization energies. Such measures always contain an influence from the closed shell reference species and will at best provide a qualitative guide to relative stabilities. As was clear from Figure 3, the isodesmic reaction used in the present work to assess thiocarbonyl stability is a reasonable qualitative predictor of reaction exothermicity, provided the differences in stabilities are large $\left(>15 \mathrm{~kJ} \mathrm{~mol}^{-1}\right)$. Thus for example the exothermicities for the lone pair donor substituted thioketones (such as $\left.\mathrm{S}=\mathrm{C}\left(\mathrm{OCH}_{3}\right) \mathrm{H}\right)$ are considerably smaller than those for $\mathrm{S}=\mathrm{CH}_{2}$, despite the fact that the adduct radicals are actually more stabilized, and this is in accord with their significantly greater thioketone stabilities. However, it is also clear that one should be cautious in attributing physical significance to more minor differences in compound stability.

Based on these trends, the most active thioketone agents should contain at least one cyano-substituent in preference to $\pi$, pseudo- $\pi$, or lone pair donor groups. However, since this not very bulky, it may not offer sufficient protection from chain termination and propagation reactions. Of the more practical possibilities, the di-tert-butyl thioketone shows the next lowest stability, which helps to explain its recent success in controlling stryene polymerization..$^{12}$ Other agents with relatively low stabilities would include the diphenyl substituted agents, especially the para-cyano-substituted ones, and also fluorene-9-thione and phenanthrene-4-thione. The other cage-like diphenyl substituted system, xanthene-9-

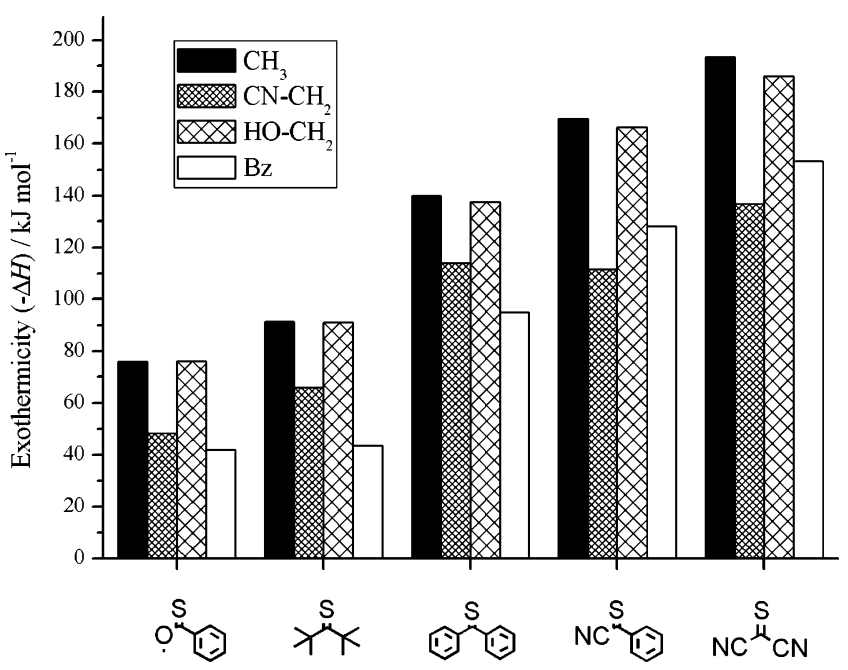

Figure 5. Exothermicities (i.e., $-\Delta H$ ) for trapping of several radicals by several thioketones at $0 \mathrm{~K}$ by all substrates studied. The values in this figure directly reflect those reported in Table 2.

thione, is much more stable than the others, due to the presence of the lone pair donating oxygen atom.

Effect of Attacking Radical. Figure 5 shows the exothermicities for addition of ${ }^{\circ} \mathrm{CH}_{3},{ }^{\circ} \mathrm{CH}_{2} \mathrm{CN},{ }^{\circ} \mathrm{CH}_{2} \mathrm{OH}$, and ${ }^{\circ} \mathrm{CH}_{2} \mathrm{Ph}$ to the various substrates. In general, it appears that the trends in the exothermicities for ${ }^{\circ} \mathrm{CH}_{3}$ addition to the various substrates provide a reasonable qualitative guide to the exothermicity trends for the other radicals. Thus, for example, of the agents considered, the methoxy-substituted agent shows the lowest exothermicities for trapping of the various radicals, the dicyano-substituted agent shows the highest, and the other substrates show intermediate behavior. Within these broad trends there are minor variations among the different attacking radicals. In particular, although the trapping of all radicals is promoted when the thioketone bears at least one cyano-substituent, the relative trapping efficiencies are reversed for the benzyl and ${ }^{\circ} \mathrm{CH}_{2} \mathrm{CN}$ radicals. This may be related to the fact that the RSE of the adduct of benzyl and $\mathrm{S}=\mathrm{C}(\mathrm{CN})_{2}$ is higher than the adducts of this substrate and the other radicals (see the bottom row of Table 2). Despite these minor variations, it appears that it may be possible to select optimal thioketone agents using calculations of their ${ }^{\circ} \mathrm{CH}_{3}$ trapping abilities, rather than calculations on larger polymeric radicals.

Comparing next the exothermicities for addition of the various radicals to a specific substrate, we note that, if we were to consider only the stability of the attacking radical, then the reactions of the least stable radical ${ }^{\circ} \mathrm{CH}_{3}$ (i.e. RSE $=0$ ) should be most exothermic, followed by those of ${ }^{\circ} \mathrm{CH}_{2} \mathrm{OH}$ and ${ }^{\circ} \mathrm{CH}_{2} \mathrm{CN}$ (RSE $=31.9$ and $31.6 \mathrm{~kJ} \mathrm{~mol}^{-1}$, respectively), ${ }^{33}$ with those of the most stable radical ${ }^{\circ} \mathrm{CH}_{2}$ $\mathrm{Ph}\left(\mathrm{RSE}=58.9 \mathrm{~kJ} \mathrm{~mol}^{-1}\right)^{33}$ expected to be the least exothermic. If we examine Table 2, we find that these trends generally hold but with two important exceptions.

First, we note that ${ }^{\circ} \mathrm{CH}_{2} \mathrm{OH}$ additions are more exothermic than one would have expected on the basis of radical stability alone. This feature has been noted previously in addition of the same radicals to alkenes, ${ }^{34}$ and its generality would seem 

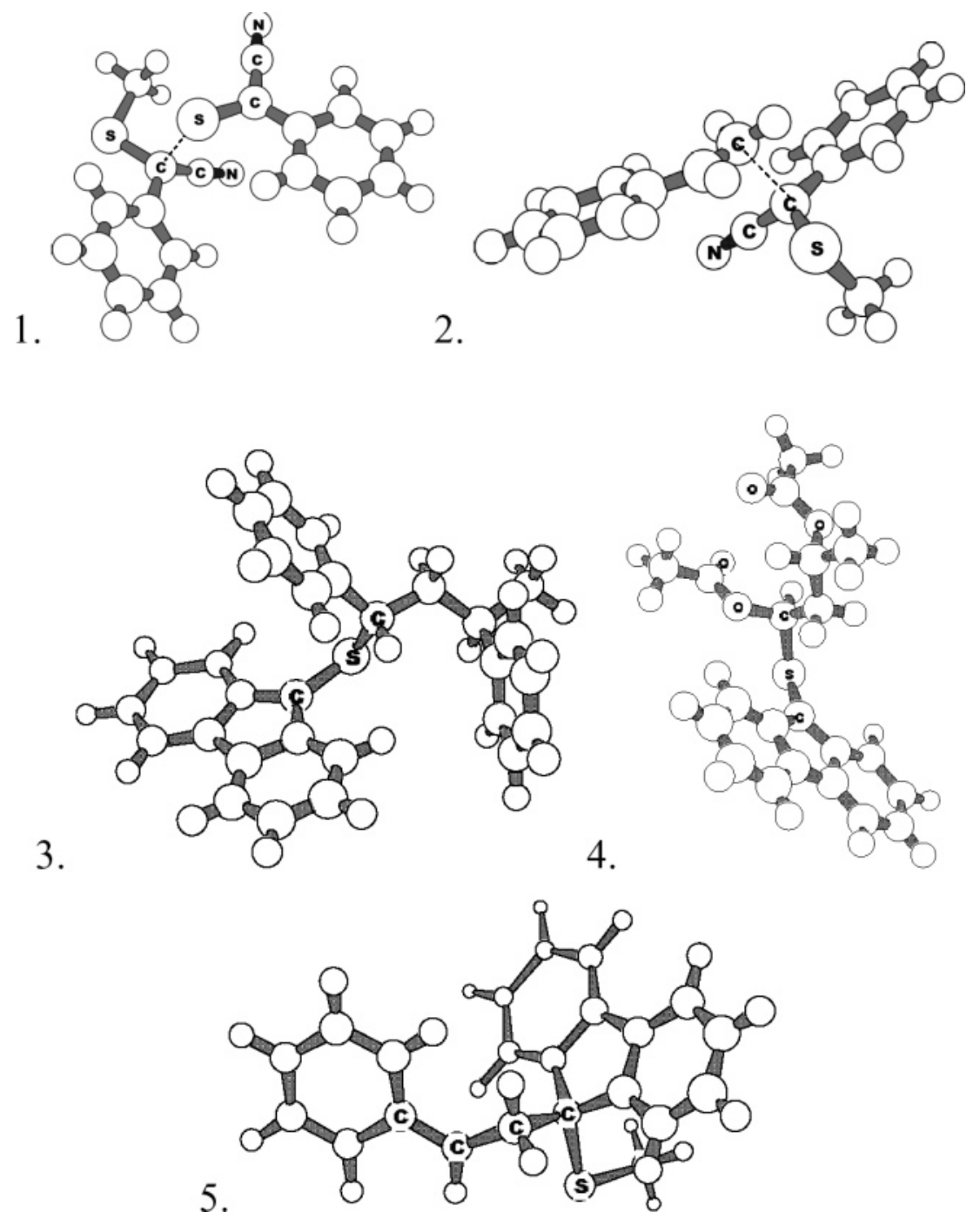

Figure 6. B3LYP/6-31G(d) optimized geometries of the transition states of (1) $\mathrm{S}=\mathrm{C}(\mathrm{CN})(\mathrm{ph})$ homopolymerizing (Scheme 2.I) and (2) $\mathrm{S}=\mathrm{C}(\mathrm{CN})(\mathrm{ph})$ copolymerizing with styrene (Scheme 2.II) as well as those of the adducts of fluorene-9-thione with (3) styryl dimer radical and (4) VA dimer radical. Structure (5) is the B3LYP/6-31G(d) optimized geometry of the adduct formed upon cross-propagation of fluorene-9-thione with styrene (Scheme 2.III).

to indicate that the ${ }^{\circ} \mathrm{CH}_{2} \mathrm{OH}$ attacking radical may actually be less stabilized than ${ }^{\circ} \mathrm{CH}_{2} \mathrm{CN}$, despite their almost identical RSEs. As explained in the Theoretical Procedures section, the RSE reflects not only the relative stabilities of the attacking radicals but also those of the corresponding closed shell compounds, and these can sometimes affect results. However, this is probably only part of the explanation: although the ${ }^{\circ} \mathrm{CH}_{2} \mathrm{OH}$ radical could easily be less stabilized than ${ }^{\circ} \mathrm{CH}_{2} \mathrm{CN}$, it is unlikely that it could be as destabilized as ${ }^{\circ} \mathrm{CH}_{3}$. Instead, it appears that the stability of the product also plays a role in the greater exothermicity for ${ }^{\circ} \mathrm{CH}_{2} \mathrm{OH}$ addition. This enhanced stability may arise through a number of factors. For example, the presence of the lone pair donor $\mathrm{OH}$ group may enhance the lone pair donation of the sulfur atom and its consequent ability to stabilize the unpaired electron of the adduct radical. To test this idea, we calculated RSEs of the various adduct radicals for a typical substrate (see Table 2) but found that those for the ${ }^{\circ} \mathrm{CH}_{3},{ }^{\circ} \mathrm{CH}_{2} \mathrm{OH}$, and ${ }^{\circ} \mathrm{CH}_{2} \mathrm{CN}$ adducts were all very similar to one another. Another possible explanation for the increased exothermicity in ${ }^{\circ} \mathrm{CH}_{2} \mathrm{OH}$ addition is the formation of stabilizing $\mathrm{H}$-bonding interactions in the adduct-radical. These occur either between the $\mathrm{O}$ of the $\mathrm{OH}$ group and $\mathrm{H}$ on the substrate (in the case of $\left.\mathrm{S}=\mathrm{C}\left(\mathrm{C}\left(\mathrm{CH}_{3}\right)_{3}\right)_{2}\right)$ or between the $\mathrm{H}$ of the $\mathrm{OH}$ group and the $\mathrm{N}$ of the $\mathrm{CN}$-group or $\mathrm{O}$ of the methoxy group in the substrate (in the case of the $\mathrm{S}=\mathrm{C}(\mathrm{CN})_{2}, \mathrm{~S}=\mathrm{C}(\mathrm{CN})(\mathrm{Ph})$, and $\left.\mathrm{S}=\mathrm{C}\left(\mathrm{OCH}_{3}\right)(\mathrm{Ph})\right)$. For depictions of all of these hydrogen bonds, see Figure 3. To establish the importance of these interactions we took selected adduct radicals and recalculated the exothermicities for corresponding conformations of the adduct radicals in which the $\mathrm{OH}$ group angled away from the substrate (and hence the H-bond was inhibited). These were typically higher in energy by a small but significant amount (for example, $5.2 \mathrm{~kJ} \mathrm{~mol}^{-1}$ for the ${ }^{\bullet} \mathrm{CH}_{2} \mathrm{OH}$ adduct of $\left.\mathrm{S}=\mathrm{C}\left(\mathrm{C}\left(\mathrm{CH}_{3}\right)_{3}\right)_{2}\right)$, suggesting that $\mathrm{H}$-bonding does play a role. Finally, the adduct radicals of ${ }^{\circ} \mathrm{CH}_{2} \mathrm{OH}$ with the thioketones are substituted with two lone pair donor groups (instead of one, as in the case of the other attacking radicals), raising the possibility that an anomeric effect on the strength 
of the formed $\mathrm{R} \cdots \mathrm{S}$ bond also contributes to their enhanced stability.

Second, the relative exothermicities for addition of the ${ }^{\circ} \mathrm{CH}_{2} \mathrm{CN}$ and ${ }^{\circ} \mathrm{CH}_{2} \mathrm{Ph}$ radicals vary somewhat according to the substrate. In particular, the exothermicity for the (more stable) ${ }^{\circ} \mathrm{CH}_{2} \mathrm{Ph}$ radical is considerably higher than that for the (less stable) ${ }^{\circ} \mathrm{CH}_{2} \mathrm{CN}$ radical for those substrates bearing cyano substituents. This may be explained as follows. In the - $\mathrm{CH}_{2} \mathrm{CN}$ adducts for which the substrate contained no $\mathrm{CN}$ group $\left(\mathrm{S}=\mathrm{C}(\mathrm{Ph})_{2}, \mathrm{~S}=\mathrm{C}\left(\mathrm{C}\left(\mathrm{CH}_{3}\right)_{2}\right.\right.$, and $\left.\mathrm{S}=\mathrm{C}\left(\mathrm{OCH}_{3}\right)(\mathrm{Ph})\right)$, the lone pair on the sulfur was not parallel to the spin unpaired orbital, implying that it is not contributing to the radical stabilization significantly. The reasons for this are steric in the case of $\mathrm{S}=\mathrm{C}(\mathrm{Ph})_{2}$ and $\mathrm{S}=\mathrm{C}\left(\mathrm{C}\left(\mathrm{CH}_{3}\right)_{3}\right)_{2}$ but electronic in the case of $\mathrm{S}=\mathrm{C}\left(\mathrm{OCH}_{3}\right)(\mathrm{Ph})$, where there is competing lone pair donation from the oxygen. In the case of $\mathrm{S}=\mathrm{C}(\mathrm{CN})_{2}$ and $\mathrm{S}=\mathrm{C}(\mathrm{CN})(\mathrm{Ph})$ however, there exists the possibility for stabilization of the radical by lone pair donation from the sulfur, since the steric and competitive donation mentioned in the previous sentence are absent. Further, we note that in the geometries of all adducts coming from each possible adduct of ${ }^{\circ} \mathrm{CH}_{2} \mathrm{Ph}$ or ${ }^{\circ} \mathrm{CH}_{2} \mathrm{OH}$ with $\mathrm{S}=\mathrm{C}(\mathrm{CN})_{2}$ or $\mathrm{S}=\mathrm{C}(\mathrm{CN})$ $(\mathrm{Ph})$, the forming bond is roughly coplanar with the radical center, meaning that stabilization of the radical by the sulfur lone pair is occurring. In systems where the attacking radical is ${ }^{\circ} \mathrm{CH}_{2} \mathrm{CN}$, it seems likely that the $\mathrm{CH}_{2} \mathrm{CN}$ group is undergoing $\pi$-acceptance of the p-type lone pair on the sulfur, thereby reducing the sulfur's lone pair stabilization of the radical. This is a phenomenon which cannot exist in adducts of other attacking radicals and hence explains the reversed order of reactivity of $\mathrm{CN}$ bearing substrates toward ${ }^{\circ} \mathrm{CH}_{2}$ $\mathrm{CN}$ and ${ }^{\circ} \mathrm{CH}_{2} \mathrm{Ph}$.

Thioketone Design. As discussed above, the requirements of a thioketone to be able to control a radical polymerization are that it (a) has a high equilibrium constant for the trapping process $K=k_{\text {add }} / k_{\text {frag }}$ (see Scheme 1.VIII) and (b) forms an adduct radical with a high stability toward copolymerization or cross-termination. While $\mathrm{S}=\mathrm{C}(\mathrm{CN})_{2}$ might appear to be the best candidate based on the first criterion (see Figure 4), its nonbulky substituents most likely preclude satisfaction of the second. The agent cyanophenyl thione, $\mathrm{S}=\mathrm{C}(\mathrm{CN})$ $(\mathrm{Ph})$, also performs well with respect to the first criterion and is slightly more bulky. However, although more hindered than $\mathrm{S}=\mathrm{C}(\mathrm{CN})_{2}$ it is still unclear whether the substituents are likely to prevent the adduct radical from undergoing propagation or termination reactions.

Apart from $\mathrm{S}=\mathrm{C}(\mathrm{CN})_{2}$ and $\mathrm{S}=\mathrm{C}(\mathrm{CN})(\mathrm{Ph})$, the next two most promising reagents on the basis of methyl radical trapping exothermicities appear to be fluorene-9-thione and cyclopenta[def]phenanthrene-4-thione. These also have the desirable feature of a closed ring structure, meaning that termination or copolymerization of the thioketones would be (at least somewhat) hindered. In deciding which of these two substrates to choose for further investigation, an additional criterion has been invoked - that of synthetic feasibility. The most common methods of synthesizing thioketones involves conversion of the ketone precursor. ${ }^{35}$ Both fluorene9-one and cyclopenta[def]phenanthrene-4-one are both available commercially, however the latter only at a synthetically infeasible expense. ${ }^{36}$ For this reason, fluorene-9-thione has been chosen for further evaluation. However, calculations on the more thermodynamically optimal agent $\mathrm{S}=\mathrm{C}(\mathrm{CN})$ $(\mathrm{Ph})$ were also undertaken with a view to establishing whether it is sufficiently hindered to resist propagation reactions.

Computational Evaluation. Having selected two potential thioketone agents, $\mathrm{S}=\mathrm{C}(\mathrm{CN})(\mathrm{Ph})$ and fluorene-9-thione, it is now necessary to evaluate their potential for controlling free-radical polymerization. In the first instance, we need to establish whether the trapped radical is sufficiently hindered to prevent propagation and termination reactions from occurring. Accurate calculations of radical-radical termination reactions (including termination in situations where the radical can be delocalized into e.g. a phenyl ring), which would require expensive multireference methods, are not currently feasible on systems of this size. However, we can study the propagation behavior. For each substrate, there are two types of propagation reaction to consider: addition of the adduct radical to the thioketone ("homopropagation") and addition of the adduct radical to the monomer ("crosspropagation"). Models of these two reactions for each of the two substrates are illustrated in Scheme 2.

In the case of the smaller substrate, $\mathrm{S}=\mathrm{C}(\mathrm{CN}) \mathrm{Ph}$ thioketone, the calculated rate coefficients for these two reactions are $1.9 \cdot 10^{8} \mathrm{~L} \mathrm{~mol}^{-1} \mathrm{~s}^{-1}$ and $11 \mathrm{~L} \mathrm{~mol}^{-1} \mathrm{~s}^{-1}$ for homopropagation (I) and cross-propagation (II), respectively. Based on these results, it is clear that homopropagation of the adduct radical of cyanophenyl thione $(\mathrm{S}=\mathrm{C}(\mathrm{CN})(\mathrm{Ph}))$ is a significant reaction. Since the steric bulk at the radical center was insufficient to prevent this side reaction, it also seems likely that there will be insufficient steric bulk to prevent biradical termination and that this particular thioketone is unlikely to be suitable for the mediation of free radical polymerizations. For this reason, no further calculations were performed for cyanophenyl thione. In the case of the larger substrate, fluorene-9-thione, it seems reasonable to assume that the closed ring structure could be too hindered to undergo significant propagation reactions. Indeed, when we calculated the equilibrium constant for the addition to the smaller of the two substrates (styrene, reaction III in Scheme 2), we found that the reaction was not very thermodynamically favorable $\left(K_{333}=3.3 \times 10^{1} \mathrm{~L} \mathrm{~mol}^{-1} ; \Delta H_{333}=-63.8 \mathrm{~kJ}\right.$ $\mathrm{mol}^{-1} ; \Delta S_{333}=-190.0 \mathrm{~J} \mathrm{~mol}^{-1} \mathrm{~K}^{-1}$ ), having a ceiling temperature of only $336 \mathrm{~K}$. In other words, propagation, if it occurred at all, would be reversible and merely contribute to radical storage. We therefore selected fluorene-9-thione for further evaluation.

The next step in the evaluation is to investigate the reaction of fluorene-9-thione with the propagating radicals of common radical polymerizations and thereby determine whether the adduct radical is sufficiently stabilized (toward $\beta$-scission) to provide sufficient control. As noted in the Introduction, kinetic studies of the related living radical polymerization process, nitroxide mediated polymerization, indicate that the equilibrium constant for the addition reaction $K$ should be around $10^{9} \mathrm{~L} \mathrm{~mol}^{-1}$ in order to effect an efficient living process. ${ }^{6}$ Values lower than this can lead to hybrid behavior and loss of control; values significantly higher than this can 
Scheme 2. (I-IV) Model System Used in Calculations Relating to Copolymerization Reactions ${ }^{a}$ and (V and VI) Model System Used in Calculation of an Addition/Fragmentation Equilibrium Constant for Mediation of a Polymerization by Fluorine-9-thione

I.

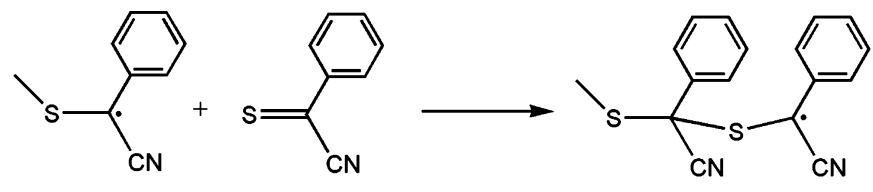

II.

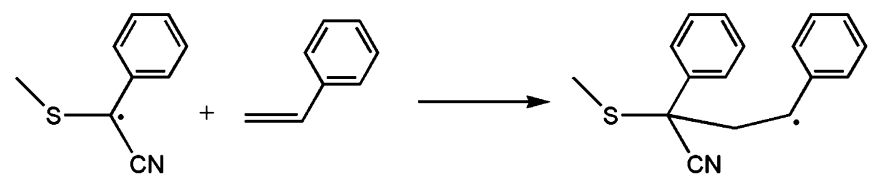

III.<smiles>CSC1c2ccccc2-c2ccccc21</smiles>
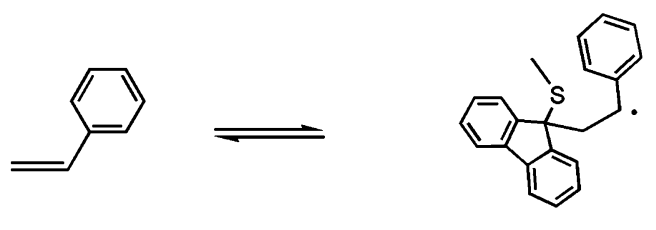

IV.
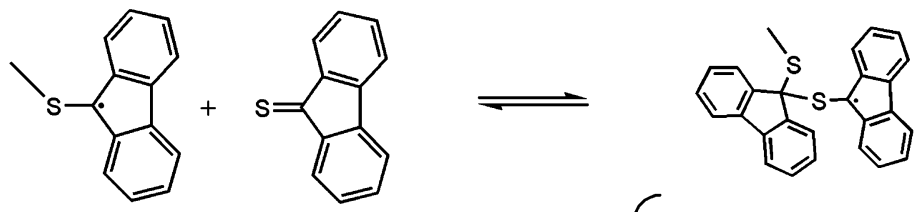

V.

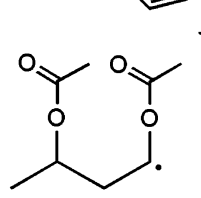

VI.<smiles>CCC(C)c1ccccc1</smiles><smiles>CCCCCC</smiles>
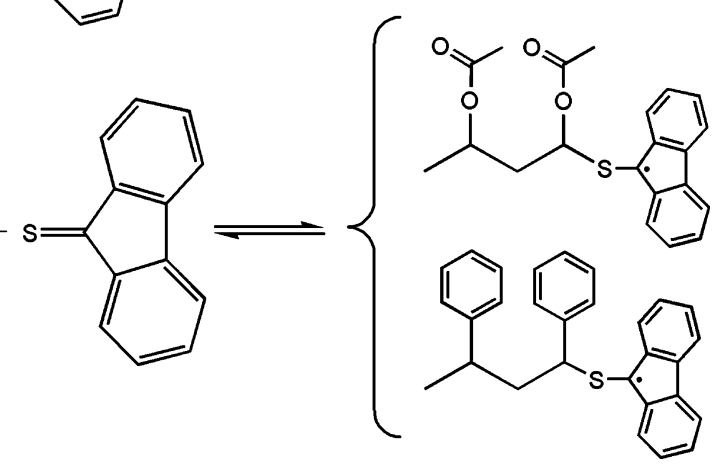

${ }^{a}$ Which must occur to a negligible extent for the thioketone to exert effective control over the polymerization.

lead to rate retardation effects. We therefore evaluated the equilibrium constant for addition of the propagating radical to fluorene-9-thione in both styrene and vinyl acetate polymerization (see reactions V and VI of Scheme 2), the former being chosen as a prototypical stable monomer, the latter as a prototypical unstable monomer. In each case, the propagating radical was modeled as a dimer as we have previously shown that, for propagation reactions at least, this model includes the most important substituent effects on radical reactivity and provides a reasonable guide to the propagation kinetics of the corresponding long chain radical. $^{37}$

Using these model reactions, it is found that the theoretical predictions for the equilibrium constant of a propagating poly(styrene) and poly(vinyl acetate) radical adding to fluorene-9-thione are $4.8 \cdot 10^{14} \mathrm{~mol} \mathrm{~L}^{-1}$ and $2.9 \cdot 10^{16} \mathrm{~mol} \mathrm{~L}^{-1}$, respectively. These equilibrium constants are considerably higher than those calculated previously for the reaction of a styryl dimer radical with di-tert-butyl thione (DTBT, 4.6 $\left.10^{4} \mathrm{~mol} \mathrm{~L}^{-1}\right)$, under the same conditions. ${ }^{12}$ Hence the objective of the present work, to identify a thioketone agent with radical trapping abilities superior to the existing DTBT, has indeed been met, and it is clear that the radical-trapping abilities of thioketones span a very wide range of values. Nonetheless, it is also clear that the equilibrium constants for these two systems are so large as to render it likely that they would induce rate retardation at $60^{\circ} \mathrm{C}$. However, it is important to question the physical realization of this equilibrium constant as forward and reverse rate coefficients. Although rate coefficients were not calculated for this system, it seems likely that in this highly exothermic reaction, the addition reaction is likely to be barrierless and occur with a chemically controlled rate coefficient above the diffusioncontrolled limit. Hence in the context of a polymerizing system, the steady-state equilibrium concentrations of the propagating and adduct radicals may not be achievable on the time-scale of the process, and the effective kinetically limited concentrations (and associated apparent equilibrium constant) may be quite different. It would therefore be worth investigating the behavior of fluorene-9-thione as a potential control agent, despite its high $K$ value. If however, rate retardation and inhibition effects are observed, hindered thioketones showing intermediate radical affinities between di-tert-butyl-thione and fluorine-9-thione, such as xanthene9-thione (see Figure 4), could be adopted instead.

\section{Conclusion}

The enthalpies at $0 \mathrm{~K}$ for radical trapping by a number of thioketones $(\mathrm{S}=\mathrm{C}(\mathrm{X})(\mathrm{Y}))$ have been evaluated via high level $\mathrm{ab}$ initio molecular orbital calculations. By altering the $\mathrm{X}$ 
and $\mathrm{Y}$, a degree of control can be exerted over the radical affinity. In general terms, the adduct radical is favored by $\pi$ accepting substituents, which delocalize and therefore stabilize the unpaired electron, and sigma accepting substituents, which weaken the $\mathrm{C}=\mathrm{S}$ bond. In contrast, due to the preexisting lone pair on the sulfur, additional lone pair substituents (such as $\mathrm{X}=\mathrm{OCH}_{3}$ ) do not afford as significant a stabilization as might have been expected, had they been in isolation. Other features of the thioketone substrates, such as how phenyl groups are attached to the rest of the molecule, can also affect the radical affinities of these compounds. In particular, twin phenyl bearing substrates (such as fluorene9-thione), for which the phenyls were linked and held in a plane, form a radical adduct in which a contiguous region of spin delocalization is spread over most of the molecule and are able to strongly stabilize the radical. As well as radical affinity, additional molecular features were highlighted which might enhance or make less suitable a particular thioketone for use in controlling a radical polymerization. Of particular importance is the steric bulk at the adduct radical center, which provides a barrier toward biradical termination of two thioketone terminated polymer chains or co/homopolymerization of the thioketone molecules.

On the basis of radical affinities, steric demands, and synthetic feasibility, fluorene-9-thione was selected as being a potentially suitable candidate for use in controlling free radical polymerizations. Cyanophenyl thione also displayed excellent radical trapping abilities but was not sufficiently hindered to prevent homopropagation side reactions. For the fluorene-9-thione, equilibrium constants (at $333.15 \mathrm{~K}$ ) in the vicinity of $10^{14} \mathrm{~L} \mathrm{~mol}^{-1}$ and $10^{16} \mathrm{~L} \mathrm{~mol}^{-1}$ were obtained for trapping of dimeric styryl and vinyl acetate radicals, respectively. Although these may be too high to achieve nonretarded polymerizations at this temperature, they indicate that there is sufficient scope within the thioketone class of compounds to mediate free radical polymeriations via radical stability alone, and other thioketones with intermediate radical trapping abilities (such as xanthene-9-thione) should be suitable for controlling free-radical polymerization.

Acknowledgment. This work was produced with the support of the Australian Research Council under the ARC Centres of Excellence program. M.L.C. also gratefully acknowledges generous allocations of computing time from the National Facility of the Australian Partnership for Advanced Computing and the Australian National University Supercomputing Facility and helpful discussions with Professor Leo Radom and Professor Chris Easton. H.C.M. acknowledges a University of New South Wales Post-Graduate Award.

Supporting Information Available: B3-LYP/6-31G(d) optimized geometries (in the form of GAUSSIAN archive entries) for the radicals, alkanes, and thioketone compounds used in the calculation of the radical stabilization energies, enthalpies, and equilibrium constants (Table S1) and all fragments which were the subject of hindered rotor calculations and the rotational potentials of all rotating fragments and their assigned frequencies (Table S2). This material is available free of charge via the Internet at http://pubs.acs.org.

\section{References}

(1) Hawker, C. J.; Bosman, A. W.; Harth, E. Chem. Rev. 2001, 101, 3661-3688.

(2) Matyjaszewski, K. Controlled/Living Radical Polymerisation; American Chemical Society: Washington, DC, 2000.

(3) Wang, J.-S.; Matyjaszewski, K. J. Am. Chem. Soc. 1995, 117, 5614-5615.

(4) Le, T. P. T.; Moad, G.; Rizzardo, E.; Thang, S. H. PCT Int Appl WO 9801478 A1 980115, 1998; Chem. Abstr. 1998, 128, 115390. (b) Charmot, D.; Corpart, P.; Michelet, D.; Zard, S. Z.; Biadatti, T. PCT Int Appl WO 9858974, 1998; Chem. Abstr. 1999, 130, 82018.

(5) Moad, G.; Rizzardo, E.; Thang, S. H. Aust. J. Chem. 2005, $58,379-410$.

(6) Goto, A.; Fukuda, T. Prog. Polym. Sci. 2004, 29, 329-385.

(7) Wang, A. R.; Zhu, S.; Kwak, Y.; Goto, A.; Fukuda, T.; Monteiro, M. S. J. Polym. Sci., Part A: Polym. Chem. 2003, $41,2833-2839$.

(8) Barner-Kowollik, B.; Vana, P.; Quinn, J. F.; Davis, T. P. J. Polym. Sci. A 2002, 40, 1058.

(9) Coote, M. L.; Radom, L. J. Am. Chem. Soc. 2003, 125, 1490-1491.

(10) Feldermann, A.; Coote, M. L.; Stenzel, M. H.; Davis, T. P.; Barner-Kowollik, C. J. Am. Chem. Soc. 2004, 126, 1591515923.

(11) Coote, M. L. Macromolecules 2004, 37, 5023-5031.

(12) Ah Toy, A.; Chaffey-Millar, H.; Davis, T. P.; Stenzel, M. H.; Coote, M. L.; Barner-Kowollik, C. Chem. Commun. (Cambridge) 2006, 8, 835-837.

(13) Henry, D. J.; Coote, M. L.; Gómez-Balderas, R.; Radom, L. J. Am. Chem. Soc. 2004, 126, 1732-1740.

(14) Coote, M. L. J. Phys. Chem. A 2005, 109, 1230-1239.

(15) Coote, M. L.; Henry, D. J. Macromolecules 2005, 38, 14151433.

(16) Krenske, E. H.; Izgorodina, E. I.; Coote, M. L. In Advances in Controlled/Living Radical Polymerization; Matyjaszewski, K., Ed.; American Chemical Society: Washington, DC, 2006; in press.

(17) Coote, M. L.; Krenske, E. H.; Izgorodina, E. I. Macromol. Rapid Commun. 2006, 27, 473-497.

(18) Griller, D.; Ingold, K. Acc. Chem. Res. 1976, 9, 13-19.

(19) Benson, S. W. Thermochemical Kinetics Methods for the Estimation of thermochemical data and rate parameters; John Wiley \& Sons: 1976.

(20) Hodgson, J. L.; Coote, M. L. J. Phys. Chem. A 2005, 109, 10013-10021.

(21) These issues are also discussed in a recent review article: Zipse, H. Top. Curr. Chem. 2006, 263, 163-189.

(22) Frisch, M. J.; Trucks, G. W.; Schlegel, H. B.; Scuseria, G. E.; Robb, M. A.; Cheeseman, J. R.; Zakrzewski, V. G.; Montgomery, J. A., Jr.; Stratmann, R. E.; Burant, J. C.; Dapprich, S.; Millam, J. M.; Daniels, A. D.; Kudin, K. N.; Strain, M. C.; Farkas, O.; Tomasi, J.; Barone, V.; Cossi, M.; Cammi, R.; Mennucci, B.; Pomelli, C.; Adamo, C.; Clifford, S.; Ochterski, J.; Petersson, G. A.; Ayala, P. Y.; Cui, Q.; 
Morokuma, K.; Malick, D. K.; Rabuck, A. D.; Raghavachari, K.; Foresman, J. B.; Cioslowski, J.; Ortiz, J. V.; Stefanov, B. B.; Liu, G.; Liashenko, A.; Piskorz, P.; Komaromi, I.; Gomperts, R.; Martin, R. L.; Fox, D. J.; Keith, T.; Al-Laham, M. A.; Peng, C. Y.; Nanayakkara, A.; Challacombe, M.; Gill, P. M. W.; Johnson, B.; Chen, W.; Wong, M. W.; Andres, J. L.; Gonzalez, C.; Head-Gordon, M.; Replogle, E. S.; Pople, J. A. Gaussian 98; Gaussian, Inc.: Pittsburgh, PA, 1998.

(23) Frisch, M. J.; Trucks, G. W.; Schlegel, H. B.; Scuseria, G. E.; Robb, M. A.; Cheeseman, J. R.; Montgomery, J. A., Jr.; Vreven, T.; Kudin, K. N.; Burant, J. C.; Millam, J. M.; Iyengar, S. S.; Tomasi, J.; Barone, V.; Mennucci, B.; Cossi, M.; Scalmani, G.; Rega, N.; Petersson, G. A.; Nakatsuji, H.; Hada, M.; Ehara, M.; Toyota, K.; Fukuda, R.; Hasegawa, J.; Ishida, M.; Nakajima, T.; Honda, Y.; Kitao, O.; Nakai, H.; Klene, M.; Li, X.; Knox, J. E.; Hratchian, H. P.; Cross, J. B.; Adamo, C.; Jaramillo, J.; Gomperts, R.; Stratmann, R. E.; Yazyev, O.; Austin, A. J.; Cammi, R.; Pomelli, C.; Ochterski, J. W.; Ayala, P. Y.; Morokuma, K.; Voth, G. A.; Salvador, P.; Dannenberg, J. J.; Zakrzewski, V. G.; Dapprich, S.; Daniels, A. D.; Strain, M. C.; Farkas, O.; Malick, D. K.; Rabuck, A. D.; Raghavachari, K.; Foresman, J. B.; Ortiz, J. V.; Cui, Q.; Baboul, A. G.; Clifford, S.; Cioslowski, J.; Stefanov, B. B.; Liu, G.; Liashenko, A.; Piskorz, P.; Komaromi, I.; Martin, R. L.; Fox, D. J.; Keith, T.; Al-Laham, M. A.; Peng, C. Y.; Nanayakkara, A.; Challacombe, M.; Gill, P. M. W.; Johnson, B.; Chen, W.; Wong, M. W.; Gonzalez, C.; Pople, J. A. Gaussian 03, Revision B03; Gaussian, Inc.: Pittsburgh, PA, 2003.

(24) Schmidt, M. W.; Baldridge, K. K.; Boatz, J. A.; Elbert, S. T.; Gordon, M. S.; Jensen, J. J.; Koseki, S.; Matsunaga, N.; Nguyen, K. A.; Su, S.; Windus, T. L.; Dupuis, M.; Montgomery, J. A. J. Comput. Chem. 1993, 14, 1347-1363.

(25) Werner, H.-J.; Knowles, P. J.; Amos, R. D.; Bernhardsson, A.; Berning, A.; Celani, P.; Cooper, D. L.; Deegan, M. J. O.; Dobbyn, A. J.; Eckert, F.; Hampel, C.; Hetzer, G.;
Korona, T.; Lindh, R.; Lloyd, A. W.; McNicholas, S. J.; Manby, F. R.; Meyer, W.; Mura, M. E.; Nicklass, A.; Palmieri, P.; Pitzer, R.; Rauhut, G.; Schütz, M.; Stoll, H.; Stone, A. J.; Tarroni, R.; Thorsteinsson, T. MOLPRO 2000.6; University of Birmingham: Birmingham, 1999.

(26) Coote, M. L.; Wood, G. P. F.; Radom, L. J. Phys. Chem. A 2002, 106, 12124-12138.

(27) Izgorodina, E. I.; Coote, M. L. J. Phys. Chem. A 2006, 110, 2486-2492.

(28) Martin, J. M. L.; de Oliveira, G. J. Chem. Phys. 1999, 111, $1843-1856$.

(29) Parthiban, S.; Martin, J. M. L. J. Phys. Chem. 2001, 114, 6014-6029.

(30) Henry, D. J.; Sullivan, M. B.; Radom, L. J. Chem. Phys. 2003, 118, 4849-4860.

(31) These formulas are described in full in the following: Coote, M. L. In Encyclopedia of Polymer Science and Technology; Kroschwitz, J. I., Ed.; Wiley: New York, 2004; pp 319371.

(32) Heuts, J. P. A. In Handbook of Radical Polymerization; Matyjaszewski, K., Davis, T. P., Eds.; John Wiley and Sons: New York, 2002; pp 1-76.

(33) Henry, D. J.; Parkinson, C. J.; Mayer, P. M.; Radom, L. J. Phys. Chem. A 2001, 105, 6750-6756.

(34) Wong, M. W.; Pross, A.; Radom, L. J. Am. Chem. Soc. 1994, 116, 6284-6292.

(35) A typical conversion employs Lawesson's reagent, for a review, see: Jesberger, M.; Davis, T. P.; Barner, L. SynthesisStuttgart 2003, 13, 1929-1958.

(36) As listed at http://wwwsigmaaldrichcom (accessed Jan 9, 2006).

(37) Izgorodina, E. I.; Coote, M. L. Chem. Phys. 2006, 324, 96-110.

CT600128T 